Article

\title{
Elevated Photovoltaic Performance in Medium Bandgap Copolymers Composed of Indacenodi- thieno[3,2-b]thiophene and Benzothiadiazole Subunits by Modulating the $\pi$-Bridge
}

\author{
Lili An ${ }^{1, *}$, Junfeng Tong ${ }^{2, * \mathbb{D}}$, Yubo Huang ${ }^{2}$, Zezhou Liang ${ }^{2}$, Jianfeng Li ${ }^{2} \mathbb{D}$, Chunyan Yang ${ }^{2}$ \\ and Xunchang Wang ${ }^{3}$ \\ 1 Key Laboratory for Utility of Environment-Friendly Composite Materials and Biomass in University of \\ Gansu Province, School of Chemical Engineering, Northwest Minzu University, Lanzhou 730030, China \\ 2 School of Materials Science and Engineering, Lanzhou Jiaotong University, Lanzhou 730070, China; \\ yubohuang94@163.com (Y.H.); zezhouliang@hotmail.com (Z.L.); ljfpyc@163.com (J.L.); \\ YChY-5@126.com (C.Y.) \\ 3 CAS Key Laboratory of Bio-Based Materials, Qingdao Institute of Bioenergy and Bioprocess Technology, \\ Chinese Academy of Sciences, Qingdao 266101, China; wang_xc@qibebt.ac.cn \\ * Correspondence: anlili2011@163.com (L.A.); tongjunfeng139@163.com (J.T.); Tel.: +86-931-495-6022 (J.T.)
}

Received: 1 December 2019; Accepted: 13 January 2020; Published: 7 February 2020

check for updates

\begin{abstract}
Two random conjugated polymers (CPs), namely, PIDTT-TBT and PIDTT-TFBT, in which indacenodithieno[3,2-b]thiophene (IDTT), 3-octylthiophene, and benzothiadiazole (BT) were in turn utilized as electron-donor (D), $\pi$-bridge, and electron-acceptor (A) units, were synthesized to comprehensively analyze the impact of reducing thiophene $\pi$-bridge and further fluorination on photostability and photovoltaic performance. Meanwhile, the control polymer PIDTT-DTBT with alternating structure was also prepared for comparison. The broadened and enhanced absorption, down-shifted highest occupied molecular orbital energy level $\left(E_{\mathrm{HOMO}}\right)$, more planar molecular geometry thus enhanced the aggregation in the film state, but insignificant impact on aggregation in solution and photostability were found after both reducing thiophene $\pi$-bridge in PIDTT-TBT and further fluorination in PIDTT-TFBT. Consequently, PIDTT-TBT-based device showed 185\% increased PCE of $5.84 \%$ profited by synergistically elevated $V_{\mathrm{OC}}, J_{\mathrm{SC}}$, and FF than those of its counterpart PIDTT-DTBT, and this improvement was chiefly ascribed to the improved absorption, deepened $E_{\mathrm{HOMO}}$, raised $\mu_{\mathrm{h}}$ and more balanced $\mu_{\mathrm{h}} / \mu_{\mathrm{e}}$, and optimized morphology of photoactive layer. However, the dropped PCE was observed after further fluorination in PIDTT-TFBT, which was mainly restricted by undesired morphology for photoactive layer as a result of strong aggregation even if in the condition of the upshifted $V_{\mathrm{OC}}$. Our preliminary results can demonstrate that modulating the $\pi$-bridge in polymer backbone was an effective method with the aim to enhance the performance for solar cell.
\end{abstract}

Keywords: indacenodithieno[3,2- $b$ ]thiophene; random conjugated polymer; modulating $\pi$-bridge; photovoltaic property

\section{Introduction}

By virtue of the intriguing features of environmentally friendly, inexhaustibility, and widespread distribution, solar energy as one kind of green renewable energy has yielded more and more attention [1,2]. Among the multitudinous solar energy utilization technologies, bulk-heterojunction (BHJ) polymer solar cells (PSCs) whose photoactive layer consists of $p$-type $\pi$-conjugated polymers 
(CPs) and $n$-type small molecules (i.e., PCBM or ITIC etc.) have received an increasing attention because of excellent superiorities, such as, low-cost, light weight, mechanical flexibility, and low temperature solution processing [3-7]. To date, power conversion efficiencies (PCEs) of PSCs have surpassed over $11 \%$ [8] in fullerene-accepter system and 15\% in non-fullerene system [9], respectively, profited by the design of novel materials, optimization of morphology for photoactive layer and the deepened understanding of the structure-performance relationship [4,10-18]. In the past decades, tremendous efforts have been devoted to design and explore donor-acceptor (D-A) type CPs since their absorption, energy levels, molecular planarity, and thus charge mobility and morphology could be finely regulated by means of judiciously selecting the D and A subunits and alternating them into the polymer backbone so as to tune the photo-induced intramolecular charge transfer (ICT) effect [19-24]. With the benefits of the designing strategy, many excellent D-A copolymers involving PBDT-DTNT [25], PNTz4T-2OD [4], PDTBDT-BT [26], PM6 [27], PBDB-T-SF [28], and J61 [29] etc., have been developed. By comparison with the fully developed low band gap (LBG, $E_{\mathrm{g}}<1.6 \mathrm{eV}$ ) copolymers, medium band gap (MBG, $1.6<E_{\mathrm{g}}<1.8 \mathrm{eV}$ ) and/or wide band gap (WBG, $E_{\mathrm{g}}>1.8 \mathrm{eV}$ ) copolymers were relatively less of concern [30,31]. However, MBG and WBG copolymers were still of importance in the PSCs, because the relatively large band gap cannot only render the low-lying highest occupied molecular orbital energy level $\left(E_{\mathrm{HOMO}}\right)$ in order to achieve the higher open-circuit voltage $\left(V_{\mathrm{OC}}\right)$, but also couple with the electron-acceptor so as to broaden the absorption range and to garner the high short-circuit current density (JSC) [32-34]. Consequently, it was of significant importance and highly essential to explore the new MBG and WBG copolymers and make a thorough inquiry of the structure-performance relationship.

Recently, highly coplanar aromatic/heteroaromatic units have attracted tremendous interest, because they possessed the following characteristics: (i) the elongated effective conjugation and improved overlap of $\pi$-orbitals along the polymer backbone direction in order to facilitate electron delocalization, which was instrumental in gaining a red-shifted absorption spectra to capture sunlight; (ii) the better intermolecular charge carrier hopping and restrained the interannular rotation so as to reduce the Marcus reorganization energy that could affect the rate of charge hopping, leading to an improved intrinsic charge mobility [22,24,35-37]. One representative ladder-type penta-ring indacenodithiophene (IDT) unit, by covalently fusing the outer thiophene rings into the central benzene core, has gained tremendous interest because of the following merits: (i) better coplanarity, highly electron density originated from large fused system, and desirable mobility; (ii) the bridge carbon ( $\mathrm{sp}^{3}$ hybridization) which can be easily replaced by the heteroatoms such as $\mathrm{Si}, \mathrm{Ge}, \mathrm{N}$, and S; (iii) multiple sites which can bond different side chain to ensure good solubility and solution-processability [37-40]. Therefore, substantial IDT-based and IDT-extended hepta-ring indacenodithieno[3,2-b]thiophene (IDTT)-based CPs have been developed [41-49]. The PCE was increased from 5.97 to $7.03 \%$ when a penta-ring IDT was replaced with an extending $\pi$-conjugation IDTT along the linear backbone [41]. Moreover, IDTT-T1 exhibited increased carrier mobility and more balanced carrier transport than that of IDT-T1 and thus the PCE was optimized from 6.26 to $6.58 \%$ [48]. When IDTT was further expanded to an undeca-ring IDT-biscyclopenta[2,1-b:3,4- $b^{\prime}$ ]dithiophene (IDTCPDT), in which the central IDT core was fused by bilateral CPDT units, the synthesized fully rigidified PIDTCPDT-DFBT exhibited more wider and stronger absorption band, decreased reorganizational energy from 4.1 to $3.2 \mathrm{kcal} \mathrm{mol}^{-1}$, and 15 -fold-elevated hole mobility and thus the $40 \%$ increased $J_{\mathrm{SC}}$ [36]. In addition to selecting the appropriate electron-rich D and electron-deficient A units to construct the efficient D- $\pi$-A type CPs, it has been proved that the conjugated $\pi$-bridges, usually consisting of conjugated subunits with small volume (i.e., thiophene (T), 2,2'-bithiophene (2T), thieno[3,2-b] thiophene (T), furan, selenophene (SeT), thiazole (Tz) and so on), played the vital role in constructing the highly efficient copolymers since these conjugated $\pi$-bridges not only linked the D and A moieties in the CPs within the D- $\pi$-A type structure, but also hindered the $\mathrm{D}$ and $\mathrm{A}$ units [38,43,50-66]. By inserting the flanked thiophene bridge on the two sides of thiadiazole[3,4-c]pyridine (PyT) or dibenzothiophene-S,S-dioxide units, the elevated $E_{\mathrm{HOMO}}$ never evidently down-shifted the $V_{\mathrm{OC}}$ and thus the increased PCE were achieved due to an improved 
FF [38,67]. For naohtho[1,2-c:5,6-c' $]$ bis[1,2,3]triazole (TZNT) system, the adding of thiophene bridge enabled the red-shifted absorption and in turn a slightly increased $J_{\mathrm{SC}}$, however the rising $E_{\mathrm{HOMO}}$ severely limited the $V_{\mathrm{OC}}$, leading to a deteriorated PCE [58]. Extending the $\pi$-bridge from thiophene to TT, multiple investigation systems consisting of benzothiadiazole (BT) [51], difluoro-substituted-BT [43], dialkyloxy-substituted BT [54,64], thieno[3,4-c]pyrrole-4,6-dione (TPD) [56], thiazolo[5,4-d]thiazole (TzTz) [62] and so on were systematically investigated and the optimized PCEs were achieved. In parallel, no remarkable improvement of PCE in BDT-alt-fluorinated quinoxaline series [53] and even a decreased PCE in IDTT-alt-TzTz system [42] were observed after replacing thiophene with an enlarged TT. When substituting of thiophene with 2T, the improvement of PCE from $1.55 \%$ to $3.34 \%$ for TT-alt-BT system and one from $2.97 \%$ to $5.07 \%$ for IDT-alt-naphtho[1,2-c:5,6-c']bis(1,2,5-thiadiazole) system were achieved principally benefited from the broadened absorption and optimized morphology of the photoactive layer $[44,57]$. The $\pi$-bridge effect of furan, thiophene, and TT on PV performance in BDT-alt-BT-based copolymers was investigated, and the gradually upshifted PCE from $2.81 \%$ to $3.72 \%$ to $4.93 \%$ profited from broadened absorption and elevated hole mobility and thus increased $J_{\mathrm{SC}}$ and $F F$ in spite of a decreased $V_{\mathrm{OC}}$ as a result of the raised $E_{\mathrm{HOMO}}$ was observed [50]. In IDTT-alt-benzo[1,2-c:4,5-c $\left.c^{\prime}\right]$ dithiophene-4,8-dione (BDD)-based copolymer system, the thiophene bridge was substituted by selenophene and thiazole, and the PCE first increased then decreased from $7.04 \%$ to $8.65 \%$ then to $2.75 \%$ [65]. Interestingly, the thiazole bridge orientation in PTBTz-2 produced a widened absorption, deepened $E_{\mathrm{HOMO}}$, more planar configuration and thus 4.14-times higher PCE than that of PTBTz-5 [61]. Recently, our group cut down the thiophene bridge to prepare two random CPs PDTBDT-SBT and PDTBDT-SFBT, and found that there existed the almost unchanged band gaps in films, gradually increased $E_{\mathrm{HOMO}}$ levels, enhanced $\pi-\pi$ stacking interaction, and the first decreased then increased photostability, when the number of the 3-octylthiophene bridge in each repeat unit varied from 0 to 1 and then up to 2 [18]. Besides, fluorination has also been proven to be a facile and effective strategy aiming at designing efficient $\mathrm{CPs}$, because the energy level can be effectively descended without impairing bandgap as the result of the most electronegative nature of $\mathrm{F}$, and relatively small volume can reduce the undesirable steric hindrance, as well as the molecular ordering was promoted by abundant hydrogen bonding interaction so as to speed up the exciton dissociation and prolongate the lifetime of charge carrier by reducing Coulombic interaction assisted by the induced dipole [68-73]. It should be noted that the fluorination can improve the molecular planarity and enhance the charge mobility but would inevitably reduce CPs' solubility, resulting in the difficulty in the process of solution-processed fabrication [74]. These abovementioned results suggested that tuning the conjugated $\pi$-bridges and introducing fluorine into the polymer backbone were the facile and wise strategies that could effectively modulate the absorption, energy level, coplanarity, aggregation and charge transport, morphology of the photoactive layer, and thus the photovoltaic performance. Therefore, it is of importance to further investigate the effect of $\pi$-bridge in IDTT-consisting conjugated copolymers on the photovoltaic performance and photo-stability and further attempt to probe into the structure-property interplay.

Inspired by the upper importance and characteristic of conjugated $\pi$-bridge and fluorination, herein, two random CPs, namely PIDTT-TBT and PIDTT-TFBT coupled between an enlarged planarity bistin IDTTSn and asymmetric dibromides 4-bromo-7-(5-bromo-4-octylthien-2-yl)benzo-thiadiazole $\left(\mathrm{TBTBr}_{2}\right)$ and/or 4-bromo-7-(5-bromo-4-octylthien-2-yl)-5,6-difluorobenzothiadiazole ( $\mathrm{TFBTBr}_{2}$ ) were designed (Scheme 1). For clear comparison, the reference copolymer PIDTT-DTBT alternating IDTT and symmetric 4,7-bis(4-octyl-thien-2-yl)benzothiadiazole (DTBT) unit was also prepared. The impact of reducing thiophene $\pi$-bridge and fluorination on their absorption spectra, energy levels, aggregation, charge mobility, morphology of the photoactive layer, and thus photostability was systemically and detailly investigated. The adopted methods could broaden and increase absorption, lower $E_{\mathrm{HOMO}}$, improve the molecular planarity, and thus enhance film aggregation, but have little impact on aggregation in $\mathrm{CB}$ and photostability. Consequently, further photovoltaic measurement suggested 
that $185 \%$ increased PCE from 2.05 to $5.84 \%$ was achieved when reducing the thiophene $\pi$-bridge in PIDTT-TBT. However, the worsen PCE was observed after further introducing fluorine in PIDTT-TFBT.

\section{Materials and Methods}

\subsection{Characterization}

${ }^{1} \mathrm{H}$ NMR spectra, melting points test, $\mathrm{C}, \mathrm{H}$, and $\mathrm{N}$ elemental analyses, TGA analyses, molecular weights of polymer, UV-Vis absorption, electrochemical properties, and atomic force microscopy (AFM) and transmission electron microscopy (TEM) images were obtained according to our reported methods [75]. The photostability of polymers and thin film X-ray diffraction (XRD) were measured according to our reported methods [34].

\subsection{Materials}

All reagents were of reagent grade and purchased from Sigma-Aldrich (Shanghai) Co. (Shanghai, China), Acros (Belgium, USA), J\&K scientific (Beijing, China) and TCI (Shanghai) Chemical Co (Shanghai, China) and used without further purification, unless otherwise noted. The interlayer material 3,3'-(1,3,8,10-tetraoxoanthra[2,1,9-def:6,5,10-d' $\left.e^{\prime} f^{\prime}\right]$ diisoquinoline-2,9(1H,3H,8H,10H)diyl)bis( $N, N$-dimethylpropan-1-amine oxide) (PDINO) was bought from Derthon optoelectronic materials science technology Co LTD (Shenzhen, China). Bistin 2,8-bis(trimethyltin)-6,6,12,12-tetra(4hexylphenyl)-indacenodithieno[3,2-b]thiophene (IDTTSn) was prepared according to our reported method [34]. Symmetric dibromide 4,7-bis(5-bromo-4-octylthien-2-yl)benzo[c][1,2,5]thiadiazole $\left(\mathrm{DTBTBr}_{2}\right)$ and unsymmetric 4-bromo-7-(5-bromo-4-octylthien-2-yl)benzo[c][1,2,5]thiadiazole $\left(\mathrm{TBTBr}_{2}\right)$, as well as fluorinated 4-bromo-7-(5-bromo-4-octylthien-2-yl)-5,6-difluorobenzo[c][1,2,5]thiadiazole $\left(\mathrm{TFBTBr}_{2}\right)$ were synthesized and described in Supporting Information.

\subsection{Polymer Synthesis}

The resultant copolymers were synthesized as the following procedures: carefully purified bistin IDTTSn and dibromo-monomer $\left(\mathrm{DTBTBr}_{2}, \mathrm{TBTBr}_{2}\right.$ and $\left.\mathrm{TFBTBr}_{2}\right)$ were fully dissolved into $6 \mathrm{~mL}$ degassed dry toluene and $0.8 \mathrm{~mL} \mathrm{DMF}$ in a $25 \mathrm{~mL}$ two-neck round-bottom flask under Ar. The mixture was bubbled with $\mathrm{Ar}$ for another $20 \mathrm{~min}$ to remove $\mathrm{O}_{2}$. Thereafter, $\mathrm{Pd}_{2}(\mathrm{dba})_{3}(1.4 \mathrm{mg})$ and $\mathrm{P}(\mathrm{o}-\mathrm{tolyl})_{3}$ $(2.3 \mathrm{mg})$ were quickly added to the mixture in one portion and the solution was bubbled with $\mathrm{Ar}$ for additional $20 \mathrm{~min}$. The mixture was then vigorously refluxed for $48 \mathrm{~h}$ under $\mathrm{Ar}$, followed by the subsequent addition of 2-tri(butylstannyl)thiophene and 2-bromothiophene at an interval of $8 \mathrm{~h}$ in order to finish ending-capping. After additional reflux at $8 \mathrm{~h}$, the mixture was poured into $300 \mathrm{~mL}$ $\mathrm{MeOH}$. The precipitate was collected by filtration and the crude polymer was subjected to Soxhlet extraction successively with $\mathrm{MeOH}$, acetone, hexane, and toluene. Finally, the toluene fraction was condensed to approximately $6 \mathrm{~mL}$ and precipitated into $\mathrm{MeOH}$. The black solid was collected and completely dried under vacuum overnight to obtain the target material with a yield of $92 \sim 98 \%$.

2.3.1. Synthesis of Poly[6,6,12,12-tetra(4-hexylphenyl)indacenodithieno[3,2-b]thiophene-2,8-diyl-alt-4,7bis-(4-octylthien-2-yl)benzo[c][1,2,5]thiadiazole-5,5'-diyl] (PIDTT-DTBT)

IDTTSn (123.4 mg, $0.092 \mathrm{mmol})$ and DTBTBr $2(65.9 \mathrm{mg}, 0.092 \mathrm{mmol})$ were used to prepare the PIDTT-DTBT according to the general procedure illustrated above. A black solid possessing metallic cluster of about $139.4 \mathrm{mg}$ as reference polymer PIDTT-DTBT was obtained with a yield of $98.0 \%$. Number-average molecular weights $\left(M_{\mathrm{n}}\right)=32.4 \mathrm{kDa}, \mathrm{PDI}=1.8 .{ }^{1} \mathrm{H} \mathrm{NMR}\left(600 \mathrm{MHz}, \mathrm{CDCl}_{3}\right), \delta(\mathrm{ppm})$, 8.58 (s, ArH), 7.98 (s, ArH), 7.78 (br, ArH), 7.53 (dd, ArH), 7.41 (s, ArH), $7.23(\mathrm{~m}, \mathrm{ArH}), 7.12(\mathrm{~m}, \mathrm{ArH})$, $2.84\left(\mathrm{br}, \mathrm{CH}_{2}\right), 2.57\left(\mathrm{~m}, \mathrm{CH}_{2}\right), 1.74\left(\mathrm{br}, \mathrm{CH}_{2}\right), 1.58\left(\mathrm{~m}, \mathrm{CH}_{2}\right), 1.44\left(\mathrm{br}, \mathrm{CH}_{2}\right), 1.35-1.20\left(\mathrm{~m}, \mathrm{CH}_{2}\right), 0.87(\mathrm{t}$, $\mathrm{CH}_{3}$ ). Anal. Calcd for $\mathrm{C}_{98} \mathrm{H}_{110} \mathrm{~N}_{2} \mathrm{~S}_{7}: \mathrm{C}, 76.41 \% ; \mathrm{H}, 7.20 \%$; N, 1.82\%. Found, $\mathrm{C}, 76.21 \% ; \mathrm{H}, 7.10 \%$; N, $1.95 \%$. 
2.3.2. Synthesis of Poly[6,6,12,12-tetra(4-hexylphenyl)indacenodithieno[3,2-b]thiophene-2,8-diyl-co-7(4-octylthien-2-yl)benzo[c][1,2,5]thiadiazole-4,5'-diyl] (PIDTT-TBT)

IDTTSn (128.0 mg, $0.095 \mathrm{mmol})$ and $\mathrm{TBTBr}_{2}(46.46 \mathrm{mg}, 0.095 \mathrm{mmol})$. The random polymer PIDTT-TBT was collected as black solid possessing metallic luster (118.9 mg, yield: $93.0 \%) . M_{\mathrm{n}}=31.2$ $\mathrm{kDa}, \mathrm{PDI}=1.9 .{ }^{1} \mathrm{H}$ NMR $\left(600 \mathrm{MHz}, \mathrm{CDCl}_{3}\right), \delta(\mathrm{ppm}), 7.98(\mathrm{~s}, \mathrm{ArH}), 7.82(\mathrm{br}, \mathrm{ArH}), 7.53(\mathrm{~s}, \mathrm{ArH}), 7.41$ (s, ArH), 7.23 (dd, ArH), 7.12 (dd, ArH), $2.84\left(\mathrm{br}, \mathrm{CH}_{2}\right), 2.56\left(\mathrm{~m}, \mathrm{CH}_{2}\right), 1.74\left(\mathrm{br}, \mathrm{CH}_{2}\right), 1.58\left(\mathrm{~m}, \mathrm{CH}_{2}\right)$, $1.43\left(\mathrm{br}, \mathrm{CH}_{2}\right), 1.35-1.20\left(\mathrm{~m}, \mathrm{CH}_{2}\right), 0.86\left(\mathrm{~m}, \mathrm{CH}_{3}\right)$. Anal. Calcd for $\mathrm{C}_{86} \mathrm{H}_{92} \mathrm{~N}_{2} \mathrm{~S}_{6}: \mathrm{C}, 76.74 \% ; \mathrm{H}, 6.89 \% ; \mathrm{N}$, $2.08 \%$. Found, $\mathrm{C}, 76.51 \% ; \mathrm{H}, 6.79 \% ; \mathrm{N}, 2.18 \%$.

2.3.3. Synthesis of Poly $[6,6,12,12$-tetra(4-hexylphenyl)indacenodithieno[3,2-b]thiophene-2,8-diyl-co-7(4-octylthien-2-yl)-5,6-difluorobenzo[c][1,2,5]thiadiazole-4,5'-diyl] (PIDTT-TFBT)

IDTTSn (136.8 mg, $0.102 \mathrm{mmol})$ and TFBTBr $2(53.32 \mathrm{mg}, 0.102 \mathrm{mmol})$. The random polymer PIDTT-TFBT was collected as black solid possessing metallic luster $(130.0 \mathrm{mg}$, yield: $92.0 \%) . M_{\mathrm{n}}=$ $34.4 \mathrm{kDa}, \mathrm{PDI}=2.1 .{ }^{1} \mathrm{H}$ NMR $\left(600 \mathrm{MHz}, \mathrm{CDCl}_{3}\right), \delta(\mathrm{ppm}), 8.67(\mathrm{~s}, \mathrm{ArH}), 8.12(\mathrm{br}, \mathrm{ArH}), 7.57(\mathrm{~d}, \mathrm{ArH})$, $7.54(\mathrm{dd}, \mathrm{ArH}), 7.45(\mathrm{~s}, \mathrm{ArH}), 7.23(\mathrm{~m}, \mathrm{ArH}), 7.12(\mathrm{~m}, \mathrm{ArH}), 2.86\left(\mathrm{br}, \mathrm{CH}_{2}\right), 2.57\left(\mathrm{~m}, \mathrm{CH}_{2}\right), 1.73\left(\mathrm{br}, \mathrm{CH}_{2}\right)$, $1.60\left(\mathrm{br}, \mathrm{CH}_{2}\right), 1.43\left(\mathrm{br}, \mathrm{CH}_{2}\right), 1.35-1.20\left(\mathrm{~m}, \mathrm{CH}_{2}\right), 0.86\left(\mathrm{t}, \mathrm{CH}_{3}\right)$. Anal. Calcd for $\mathrm{C}_{86} \mathrm{H}_{90} \mathrm{~F}_{2} \mathrm{~N}_{2} \mathrm{~S}_{6}$ : C, $74.74 \%$; H, 6.56\%; N, 2.03\%. Found, C, 74.51\%; H, 6.41\%; N, 2.19\%.

\subsection{Fabrication and Characterization of PSCs}

The fabrication process for the devices used for photovoltaic performance measurement of the resultant copolymers was prepared according to our reported reference [13].

\subsection{Hole-Only Device Fabrication and Measurement}

The hole mobility of the active layer was measured from the $J-V$ curves obtained under dark current described in our reported reference using the steady state space-charge-limited-current (SCLC) method $[24,76]$.

\section{Results and Discussion}

\subsection{Molecular Design, Synthesis, and Characterization}

Key monomer bistin IDTTSn was synthesized according to our reported work [34]. Unsymmetrical dibromide $\mathrm{TBTBr}_{2}$ and $\mathrm{TFBTBr}_{2}$ are described in Scheme S1 in Supporting Information. These key intermediates and comonomers have been identified by ${ }^{1} \mathrm{H}$ NMR, as depicted in Figure S1-S5 (in Supplementary Materials) and elemental analyses. These studied random copolymers PIDTT-TBT and PIDTT-TFBT as well as the control polymer PIDTT-DTBT were prepared via typical Stille polymerization, as elucidated in Scheme 1 [77] and further purified in the light of the reported method [75]. In the end, the fraction dissolved in toluene was recovered by re-precipitating in $\mathrm{MeOH}$ and then dried under vacuum overnight so as to remove the residual solvents. Note that all polymers were obtained as black solids exhibiting metallic luster in the high yields of $92 \sim 98 \%$. It was found that these prepared copolymers displayed enough solubility in the chlorinated solvents (i.e., chloroform, chlorobenzene (CB), and o-dichlorobenzene (oDCB)), satisfying the requirements of the solution-processed fabrication procedure.

What is exciting is that the ${ }^{1} \mathrm{H}$ NMR signals placed in the aromatic regions with regard to these resultant copolymers were all clearly observed, as outlined in Figures S6-S8 (in Supplementary Materials). In detail, peaks in the range of $8.67-7.41 \mathrm{ppm}$ were produced by aromatic hydrogen from main chain of IDTT and DTBT, TBT and TFBT, and ones placed at $7.23 \mathrm{ppm}$ and $7.11 \mathrm{ppm}$ can be ascribed to aromatic hydrogen of hexylphenyl group. While, the peaks located at $2.86-2.84 \mathrm{ppm}$ was belonged to the signal of $-\mathrm{CH}_{2}$ - directly linked to the thiophene bridge and ones placed at 2.58-2.56 ppm were originated from the signal of $-\mathrm{CH}_{2}-$ directly linked to phenyl group. Furthermore, the peaks ranged from 1.74 to $1.24 \mathrm{ppm}$ were ascribed to the signals of remainder $-\mathrm{CH}_{2}-$ of flexible side chains, 
and ones at $0.86 \mathrm{ppm}$ were assigned to the signals of terminal $-\mathrm{CH}_{3}$. Besides, the results obtained from elemental analysis were found to be consistent with the theoretical values. Gel permeation chromatography (GPC) measurement exhibited the values for $M_{\mathrm{n}}$ and PDIs to be $32.4 \mathrm{kDa}$ and 1.8 for PIDTT-DTBT, 31.2 kDa and 1.9 for PIDTT-TBT, and 34.4 kDa and 2.1 for PIDTT-TFBT, respectively (Table S1 in Supplementary Materials), suggesting that the influence of the molecular weights on the optoelectronic and photovoltaic properties could be neglected. Seen from Figure S9 and Table S1 (in Supplementary Materials), the control polymer PIDTT-DTBT and two random copolymers PIDTT-TBT and PIDTT-TFBT exhibited the decomposed temperature ( $T_{\mathrm{d}}, 5 \%$ weight-loss temperature) of approximately 310,346 , and $366^{\circ} \mathrm{C}$, respectively. Obviously, random polymer PIDTT-TBT with asymmetric $\pi$-bridge and further fluorinated PIDTT-TFBT exhibited a gradually elevated $T_{\mathrm{d}}$, which was in line with the enhanced molecular planarity and ordering obtained from the latter XRD analyses and DFT calculation.
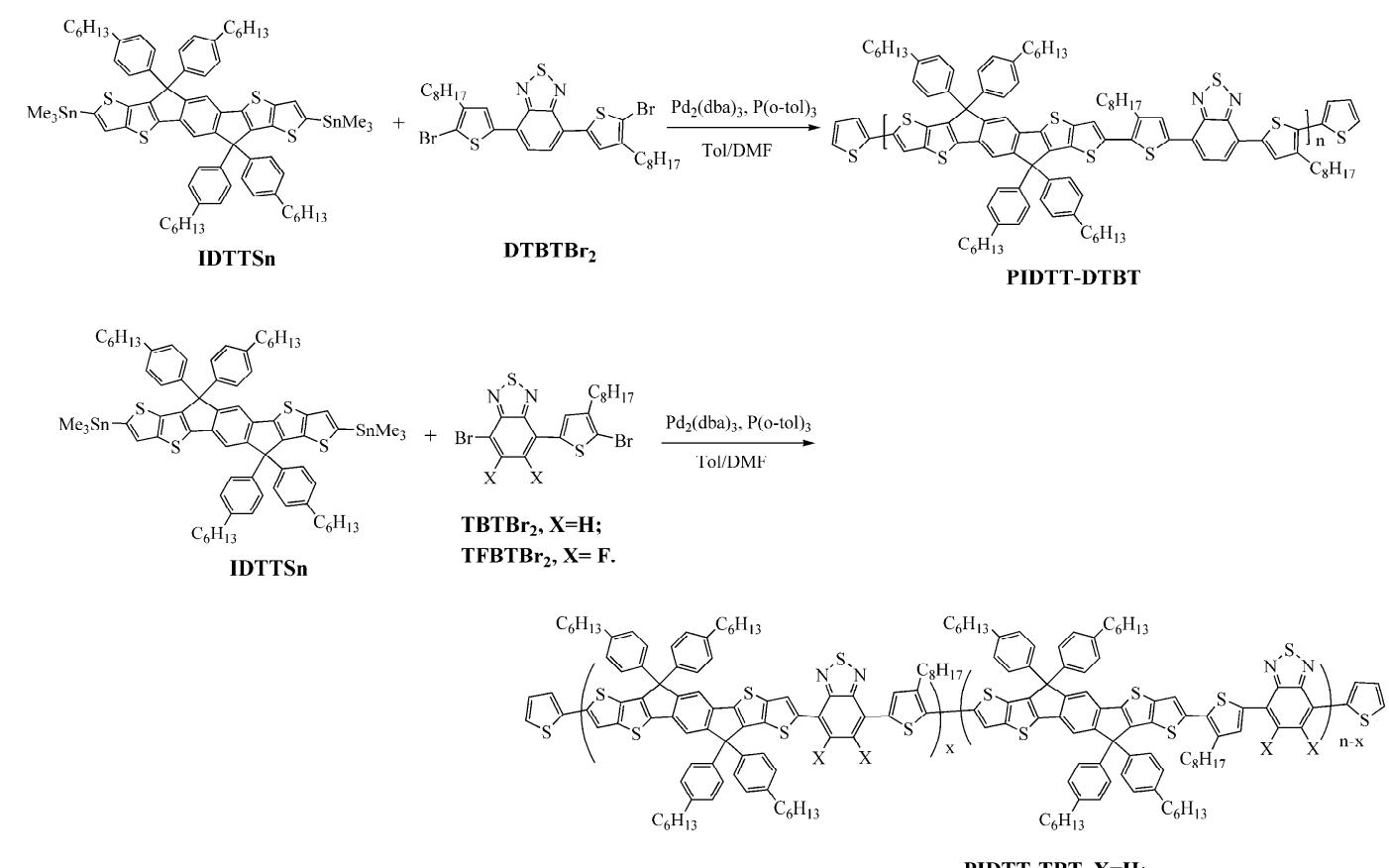

PIDTT-TBT, $\mathrm{X}=\mathrm{H}$;

PIDTT-TFBT, $X=F$.

Scheme 1. The synthetic routes of the random copolymers PIDTT-TBT and PIDTT-TFBT and the alternated copolymer PIDTT-DTBT.

\subsection{Optical Property}

In order to investigate the impact of reducing thiophene $\pi$-bridge and further fluorination on absorption behavior, the normalized UV-Vis absorption spectra in CB solution with the concentration of approximately $10^{-5} \mathrm{~mol} \mathrm{~L}^{-1}$ and as solid films were examined. As can be seen from Figure 1 and Table 1, the studied copolymers exhibited two legible absorption peaks, i.e., one situated at $350 \sim 500 \mathrm{~nm}$ were assigned to the $\pi-\pi^{*}$ transition from the resultant polymer backbone, the other one located in the range of 500 750 nm were originated from ICT effect from electron-rich IDTT unit to electron-deficient BT/FBT moiety [34,41]. After reducing the conjugated octylthiophene $\pi$-bridge and further fluorination, the decreased and blue-shifted variation (from 442 to 431 then to $428 \mathrm{~nm}$ in CB and from 445 to 436 then to $432 \mathrm{~nm}$ in film) for absorption peak in the high energy region in both $\mathrm{CB}$ and solid film was found, while only red-shifted change in the CB but both red-shifted and enhanced alternation for peak in the low energy region were also observed, these phenomena were identical with other groups' results [41,43]. Ongoing from solution to film state, the red-shifted values for the maximum absorption peaks $\left(\lambda_{\max }\right)$ of $6 \mathrm{~nm}$ for PIDTT-DTBT, $8 \mathrm{~nm}$ for PIDTT-TBT, and $18 \mathrm{~nm}$ for PIDTT-TFBT were observed, respectively. In particular, the fluorinated PIDTT-TFBT exhibited a weak 
peak seated at $590 \mathrm{~nm}$, implying an enhanced molecular aggregation and stacking interaction evoked by fluorination $[24,25,68]$. Importantly, the absorption coefficient in film state was enhanced after reducing thiophene $\pi$-bridge and further fluorination. These changes could preliminarily suggest that the studied CPs exhibited the gradually increasing aggregation ability according to the sequence of PIDTT-DTBT, PIDTT-TBT, and PIDTT-TFBT. Furthermore, the optical bandgaps $\left(E_{\mathrm{g}}^{\mathrm{opt}}\right)$ values of $1.79 \mathrm{eV}$ for PIDTT-DTBT, $1.76 \mathrm{eV}$ for PIDTT-TBT, and $1.77 \mathrm{~nm}$ for PIDTT-TFBT in films were estimated with the absorption edge $\left(\lambda_{\text {onset }}^{\text {film }}\right)$ in terms of $E_{\mathrm{g}}^{\text {opt }}=1240 / \lambda_{\text {onset' }}^{\text {film }}$, suggesting that the $E_{\mathrm{g}}^{\text {opt }}$ exhibited first reduced then slightly increased tendency in the order of PIDTT-DTBT, PIDTT-TBT, and PIDTT-TFBT. Evidently, after the thiophene $\pi$-bridge was reduced and further fluorinated, the absorption and absorption coefficient were improved, which was conducive to acquiring the higher $J_{\mathrm{SC}}$.
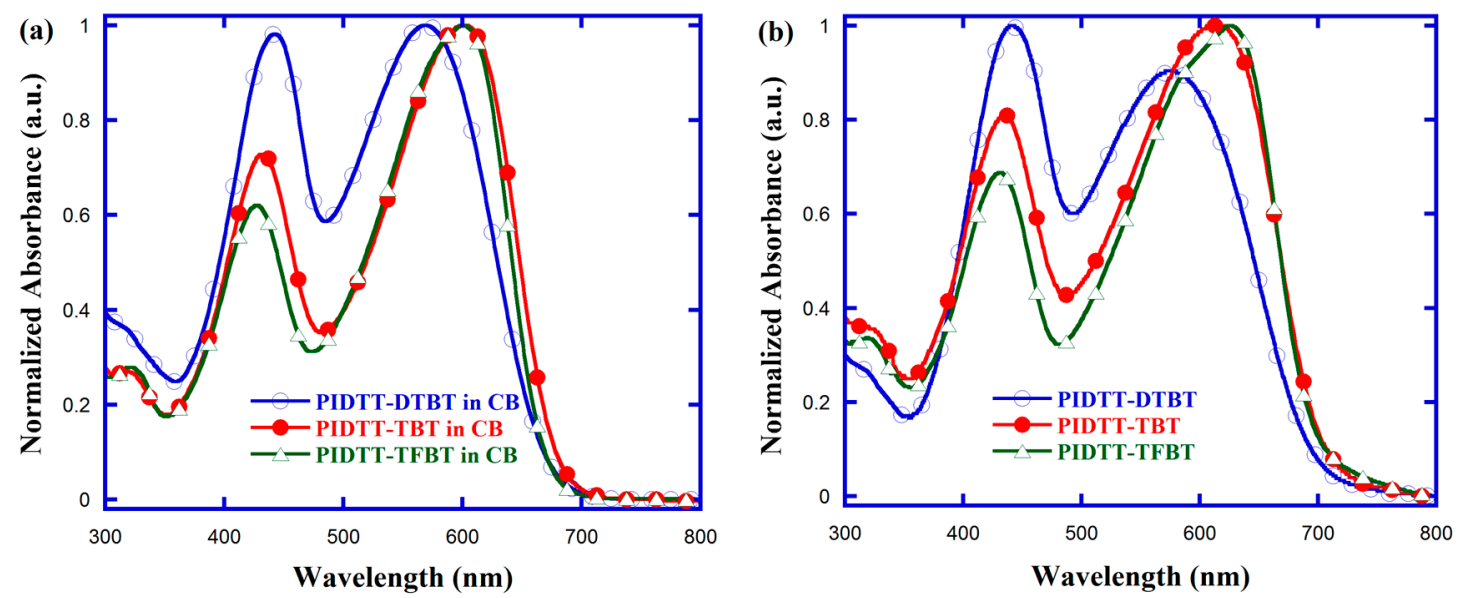

Figure 1. Normalized UV-vis absorption spectra of the resultant copolymers PIDTT-DTBT, PIDTT-TBT, and PIDTT-TFBT in diluted chlorobenzene (CB) (a) and thin film state (b).

Table 1. Optical and electrochemical properties of the copolymers.

\begin{tabular}{|c|c|c|c|c|c|c|c|c|c|c|}
\hline \multirow[b]{2}{*}{ Polymer } & \multirow{2}{*}{$\begin{array}{c}\text { Solution } \\
\lambda_{\max } \\
(\mathrm{nm})\end{array}$} & \multicolumn{3}{|c|}{ Film } & \multirow{2}{*}{$\begin{array}{c}E_{g}^{o p t} 1 \\
(\mathrm{eV})\end{array}$} & \multirow[b]{2}{*}{$\begin{array}{l}\varphi_{\text {ox }} \\
\text { (V) }\end{array}$} & \multirow[b]{2}{*}{$\begin{array}{c}\varphi_{\text {red }} \\
\text { (V) }\end{array}$} & \multirow{2}{*}{$\underbrace{E_{\text {HOMO }}}_{(\mathrm{eV})}$} & \multirow{2}{*}{$\underbrace{E_{\text {LUMO }}}_{(\mathrm{eV})}$} & \multirow[b]{2}{*}{$\begin{array}{l}E_{g}^{e c 4} \\
(\mathrm{eV})\end{array}$} \\
\hline & & $\begin{array}{l}\lambda_{\max } \\
(\mathrm{nm})\end{array}$ & $\begin{array}{c}\lambda_{\text {sh }} \\
(\mathrm{nm})\end{array}$ & $\begin{array}{c}\lambda_{\text {onset }} \\
\text { (nm) }\end{array}$ & & & & & & \\
\hline PIDTT-DTBT & $\begin{array}{l}442 \\
570\end{array}$ & $\begin{array}{l}445 \\
576\end{array}$ & - & 692 & 1.79 & 0.59 & -1.22 & -5.28 & -3.47 & 1.81 \\
\hline PIDTT-TBT & $\begin{array}{l}431 \\
602\end{array}$ & $\begin{array}{l}436 \\
610\end{array}$ & - & 705 & 1.76 & 0.66 & -1.11 & -5.35 & -3.58 & 1.77 \\
\hline PIDTT-TFBT & $\begin{array}{l}428 \\
602\end{array}$ & $\begin{array}{l}432 \\
620\end{array}$ & 590 & 702 & 1.77 & 0.73 & -1.04 & -5.43 & -3.65 & 1.77 \\
\hline
\end{tabular}

${ }^{1}$ Optical bandgap was calculated from the onset of the film absorption $\left(E_{\mathrm{g}}^{\text {opt }}=1240 / \lambda_{\text {onset }}^{\text {film }}\right){ }^{2} E_{\text {HOMO }}$ was calculated from oxidation potential of the copolymers $\left(E_{\mathrm{HOMO}}=-\mathrm{e}\left(\varphi_{\mathrm{OX}}^{\mathrm{onset}}+4.69\right)(\mathrm{eV})\right) ;{ }^{3} E_{\mathrm{LUMO}}$ was calculated from reduction potential of the copolymers $\left(E_{\mathrm{LUMO}}=-\mathrm{e}\left(\varphi_{\text {red }}^{\text {onset }}+4.69\right)(\mathrm{eV})\right) ;{ }^{4} E_{\mathrm{g}}^{\mathrm{ec}}=E_{\mathrm{LUMO}}-E_{\mathrm{HOMO}}(\mathrm{eV})$.

To examine the difference of reducing $\pi$-bridge and further fluorination on aggregation in solution, the temperature-dependent absorption (TD-Abs) spectra of the resultant copolymers in CB solution (ca. $10^{-5} \mathrm{~mol} \mathrm{~L}-1$ ) ranging from 105 to $25^{\circ} \mathrm{C}$ with a $10^{\circ} \mathrm{C}$ interval was tested [24,78]. As elucidated in Figure 2, the studied copolymers exhibited the similar variation tendency, that is, the ICT and $\pi-\pi^{*}$ absorption peak were all blue-shifted and the absorption intensity decreased with the elevating temperature. In detail, after temperature was risen from 25 to $105^{\circ} \mathrm{C}$, the blue-shifted values $(\Delta \lambda)$ and the decreased absorption intensity $(\Delta I)$ were $14 \mathrm{~nm}$ (from 570 to $556 \mathrm{~nm}$ ) and $15.1 \%$ for PIDTT-DTBT, $13 \mathrm{~nm}$ (from 602 to $589 \mathrm{~nm}$ ) and 12.1\% for PIDTT-TBT and $16 \mathrm{~nm}$ (from 602 to $586 \mathrm{~nm}$ ) and $14.4 \%$ for PIDTT-TFBT, respectively. The observed similar vibration values with respect to absorption peak and intensity implied that the strategies of reducing $\pi$-bridge and fluorination produced the little impact on aggregation in CB solution [79]. 

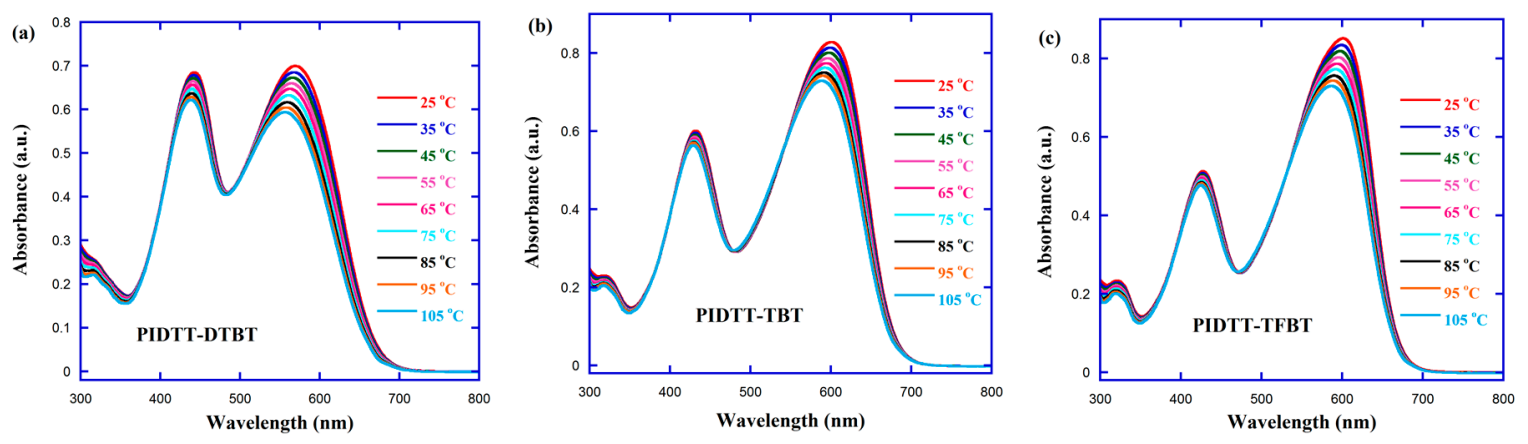

Figure 2. TD-Abs spectra for the studied copolymers PIDTT-DTBT (a), PIDTT-TBT (b), and PIDTT-TFBT (c) in CB.

\subsection{Photostability Property}

Aimed at achieving the industrialization of PSCs, in addition to the ability of harvesting sunlight, the photo-stability of organic semiconductor materials was also an important issue $[18,34,80,81]$. Consequently, in order to inspect the effect of reducing conjugated thiophene $\pi$-bridge and further fluorination on the photo-stabilities, the absorption variations of the resultant CPs were examined by exposing the diluted CB solution and the polymers' films under AM1.5 sunlight irradiation in air at room temperature. As exhibited in Figure S10 (in Supplementary Materials), we can see that after $4 \mathrm{~h}$ of photodegradation in CB solution, PIDTT-DTBT, PIDTT-TBT, and PIDTT-TFBT exhibited the almost unchanged absorption, that is to say, higher than $98 \%$ of their initial light absorption was maintained. As for the solid film, the UV-vis spectra changes of these copolymers are outlined in Figure 3. The peak related to $\pi-\pi^{*}$ transition almost remained unchanged and one assigned to ICT transition exhibited gradual descending with the time of light-soaking. In detail, $92.7 \%, 91.1 \%$, and $93.9 \%$ of their initial light absorption for PIDTT-DTBT, PIDTT-TBT, and PIDTT-TFBT after $9 \mathrm{~h}$ of illumination were seen, which was obviously superior to that of PIDTT-DTNT-based copolymers [34]. Based on the above fact, it was concluded that the strategies of reducing thiophene $\pi$-bridge and further fluorination produced very tiny impact on the photostability in both $\mathrm{CB}$ and solid film.

\subsection{X-ray Diffraction (XRD) Analysis}

X-ray diffraction (XRD) analyses of the pristine polymers were applied to further probe into the influence of reducing $\pi$-bridge and further fluorination on crystallinity and molecular packing in solid film state, as disclosed in Figure 4. It was noted that the used films were casted from CB solution onto the glass substrate. There was only one weak diffraction peak at approximately $20.45^{\circ}$ in the reference polymer PIDTT-DTBT, which was attributed to $\pi-\pi$ stacking distance of $4.34 \AA$ calculated from the Bragg's law (i.e., $\lambda=2 \mathrm{~d} \sin \theta$ ) [34]. For PIDTT-TBT and PIDTT-TFBT, there existed two distinct diffractions. The sharp diffraction peaks in a small angle region are located at $2 \theta$ of $4.13^{\circ}$ for PIDTT-TBT and $4.32^{\circ}$ for PIDTT-TFBT, corresponding to the distance of polymer backbone separated by the flexible side were 21.37 and $21.01 \AA$, respectively. While the broad diffraction peaks placed at wide angle district located at $2 \theta$ of $20.55^{\circ}$ for PIDTT-TBT and $21.98^{\circ}$ for PIDTT-TFBT could be attributed to $\pi-\pi$ stacking interaction, which reflected the corresponding $\pi-\pi$ stacking distances of 4.32 and $4.04 \AA$, respectively. It is inescapably clear that the aggregation trend in the film state was enhanced when the thiophene $\pi$-bridge was reduced and further fluorinated, which agreed with the previous phenomenon from absorption. 

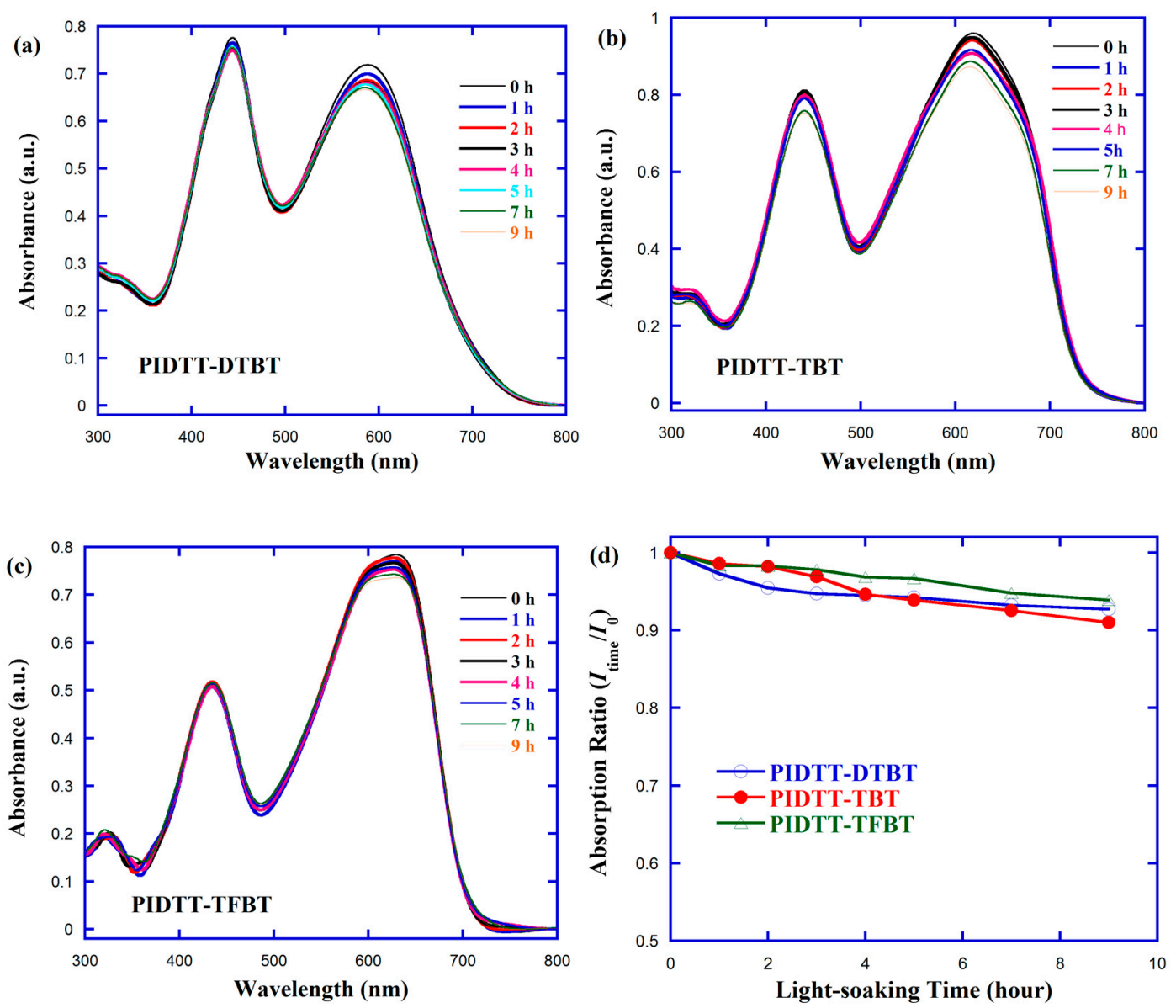

Figure 3. UV-vis absorption spectra variation after illumination of PIDTT-DTBT (a), PIDTT-TBT (b), and PIDTT-TFBT (c) films on ITO and a summary of light absorption intensity changes at the peak of each polymer as a function of light-soaking time (d).

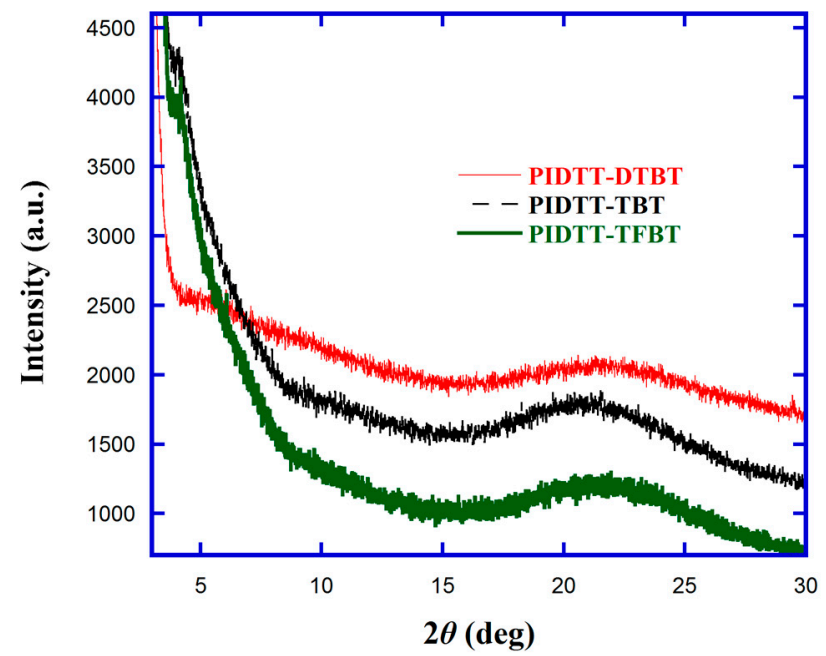

Figure 4. X-ray patterns of PIDTT-DTBT, PIDTT-TBT, and PIDTT-TFBT.

\subsection{Electrochemical Property}

Since the $E_{\mathrm{HOMO}}$ and $E_{\mathrm{LUOMO}}$ values for photovoltaic materials were regarded as important parameters for estimating the photovoltaic performance, cyclic voltammetry (CV) method was utilized to gain insight into the impact of reducing the thiophene $\pi$-bridge and further fluorination on the 
electrochemical properties. It was noted that the $E_{\mathrm{HOMO}}$ and $E_{\mathrm{LUMO}}$ were calculated from its oxidation onset potential $\left(\varphi_{\mathrm{ox}}^{\text {onset }}\right)$ and reduction onset potential $\left(\varphi_{\text {red }}^{\text {onset }}\right)$, respectively. As displayed in Figure 5a and Table 1 , the corresponding $\varphi_{\mathrm{ox}}^{\text {onset }}$ and $\varphi_{\text {red }}^{\text {onset }}$ values of 0.59 and $-1.22 \mathrm{~V}$ for PIDTT-DTBT, 0.66 and $-1.11 \mathrm{~V}$ for PIDTT-TFBT, and 0.73 and $-1.04 \mathrm{~V}$ for PIDTT-TFBT were observed, respectively. It was needed to point out that the $\mathrm{CV}$ curve was recorded relative to the potential of the standard $\mathrm{Ag} / \mathrm{AgNO}$ electrode, calibrated by the ferrocene-ferrocenium $\left(\mathrm{Fc} / \mathrm{Fc}^{+}\right)$redox pair. The $\varphi_{1 / 2}$ of the $\mathrm{Fc} / \mathrm{Fc}^{+}$redox pair was $0.11 \mathrm{~V}$ vs. $\mathrm{Ag} / \mathrm{AgNO}_{3}$ electrode. Supposing that the redox potential for $\mathrm{Fc} / \mathrm{Fc}^{+}$was $-4.80 \mathrm{eV}$ in relative to vacuum energy level, the $E_{\mathrm{HOMO}}$ can be estimated from the formula $E_{\mathrm{HOMO}}=-\mathrm{e}\left(\varphi_{\mathrm{ox}}^{\mathrm{onset}}+\right.$ $4.69)(\mathrm{eV})$ and $E_{\mathrm{LUMO}}=-\mathrm{e}\left(\varphi_{\text {red }}^{\text {onset }}+4.69\right)(\mathrm{eV})$, respectively [82]. Consequently, the $E_{\mathrm{HOMO}}$ and $E_{\mathrm{LUMO}}$ values were estimated to be -5.28 and $-3.47 \mathrm{eV}$ for PIDTT-DTBT, -5.35 and $-3.58 \mathrm{eV}$ for PIDTT-TBT, and -5.43 and $-3.65 \mathrm{eV}$ for PIDTT-TFBT, respectively. Moreover, the electrochemical bandgap $\left(E_{\mathrm{g}}^{\mathrm{ec}}\right)$ values for PIDTT-DTBT, PIDTT-TBT, and PIDTT-TFBT were calculated to be 1.81, 1.77, and $1.77 \mathrm{eV}$, respectively. In order to make a better comparison, the schematic diagram with respect to the energy levels for the resulted copolymers and electron-acceptor $\mathrm{PC}_{71} \mathrm{BM}$ is depicted in Figure $5 \mathrm{~b}$. It was seen that the decreasing $E_{\mathrm{HOMO}}$ values ca. 0.07 and $0.15 \mathrm{eV}$ were observed after reducing the thiophene $\pi$-bridge and further fluorination, respectively. This change trend was instrumental in yielding the higher $V_{\mathrm{OC}}$, since the $V_{\mathrm{OC}}$ was maximized with the enlarging difference between the $E_{\mathrm{HOMO}}$ of donor and $E_{\mathrm{LUMO}}$ of the acceptor $[3,83]$. Simultaneously, the differences between $E_{\mathrm{LUMO}}$ of donor polymers and one of $E_{\mathrm{LUMO}}$ of $\mathrm{PC}_{71} \mathrm{BM}$ ranged from 0.55 to $0.73 \mathrm{eV}$, which could support enough driving force to promote the exciton to dissociate into free charge at the D-A interfaces [3]. Theoretically, these decreased $E_{\mathrm{HOMO}}$ levels and the lowered bandgaps were hopeful for improving the $V_{\mathrm{OC}}$ and $J_{\mathrm{SC}}$, and thus resulting in the enhanced PCE.
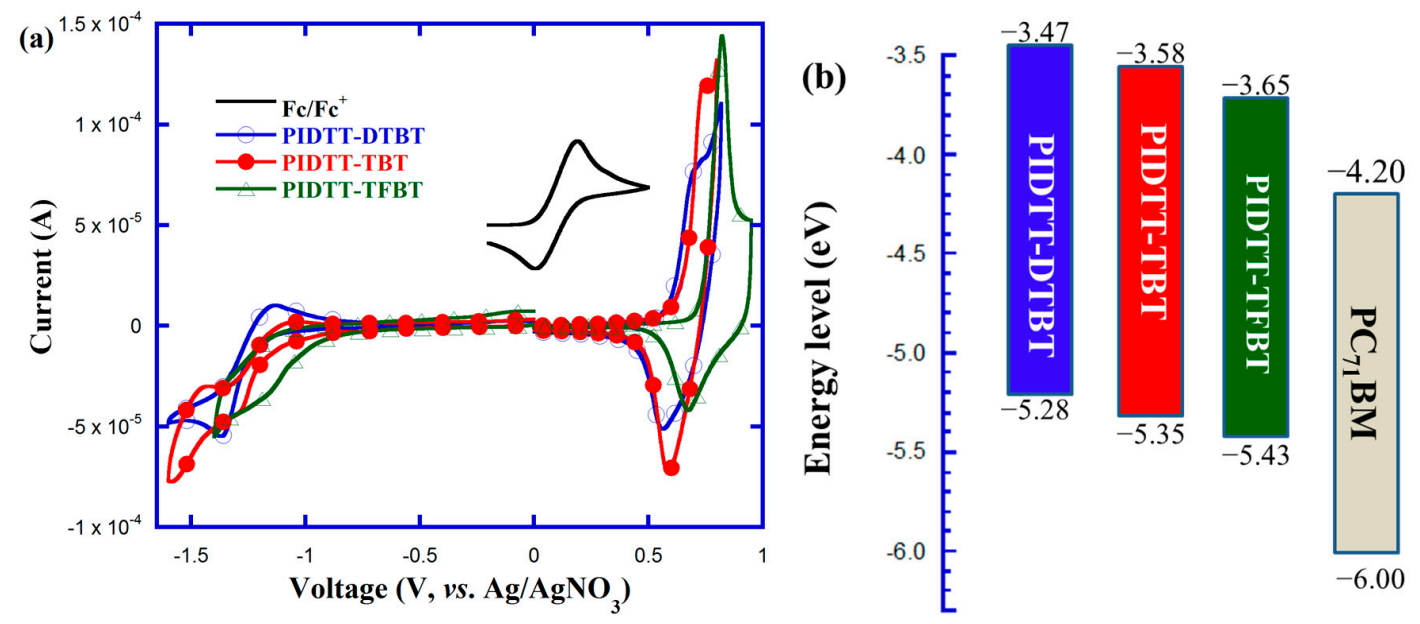

Figure 5. CV curves (a) and energy levels schematic diagram (b) of copolymers PIDTT-DTBT, PIDTT-TBT, and PIDTT-TFBT.

\subsection{Theoretical Calculation}

The density functional theory (DFT) calculation situated at B3LYP/6-31G* basis set (Gaussian 09) was selected to further probe into the effect of reducing thiophene $\pi$-bridge and further fluorination on the molecular backbone conformation and the electron density distributions [84]. For simplification, the hexyl side chain from IDTT and octyl side chain attached onto the thiophene bridge were both replaced with the methyl, and oligomers involving one repeating unit (unimer) were used to take the place of the corresponding polymer backbones. Note that the unimer model for the studied random copolymers PIDTT-TBT and further fluorinated PIDTT-TFBT had two different linking patterns, (IDTT-BT-T) and/or (IDTT-T-BT), and (IDTT-FBT-T) and/or (IDTT-T-FBT), respectively. As presented in Figure 6, the HOMO orbitals of all studied compounds are primarily delocalized across the whole conjugated main chain, in contrast, the LUMO orbitals are preferentially distributed in electron-deficient 
BT and/or FBT and lateral thiophene bridges, indicating that there existed the relatively obvious charge-transfer effect from IDTT to BT and/or FBT units. It was seen that the theoretically forecasted values for $E_{\mathrm{HOMO}}, E_{\mathrm{LUMO}}$, and bandgap were $-4.94,-2.80$, and $2.14 \mathrm{eV}$ of PIDTT-DTBT, $-4.97,-2.79$, and $2.18 \mathrm{eV}$ of IDTT-BT-T, and $-4.99,-2.69$, and $2.30 \mathrm{eV}$ of IDTT-BT-T for thiophene-bridge-reducing PIDTT-TBT, $-5.04,-2.90$, and $2.14 \mathrm{eV}$ for PIDTT-FBT-T and $-5.02,-2.86$, and $2.16 \mathrm{eV}$ of IDTT-T-FBT for further fluorinated PIDTT-TFBT, respectively. We can see that, regardless of the position of thiophene $\pi$-bridge, the descending trend of $E_{\mathrm{HOMO}}$ from PIDTT-DTBT to PIDTT-TBT then to PIDTT-TFBT was observed, which was in accordance with the results obtained from CV testing.

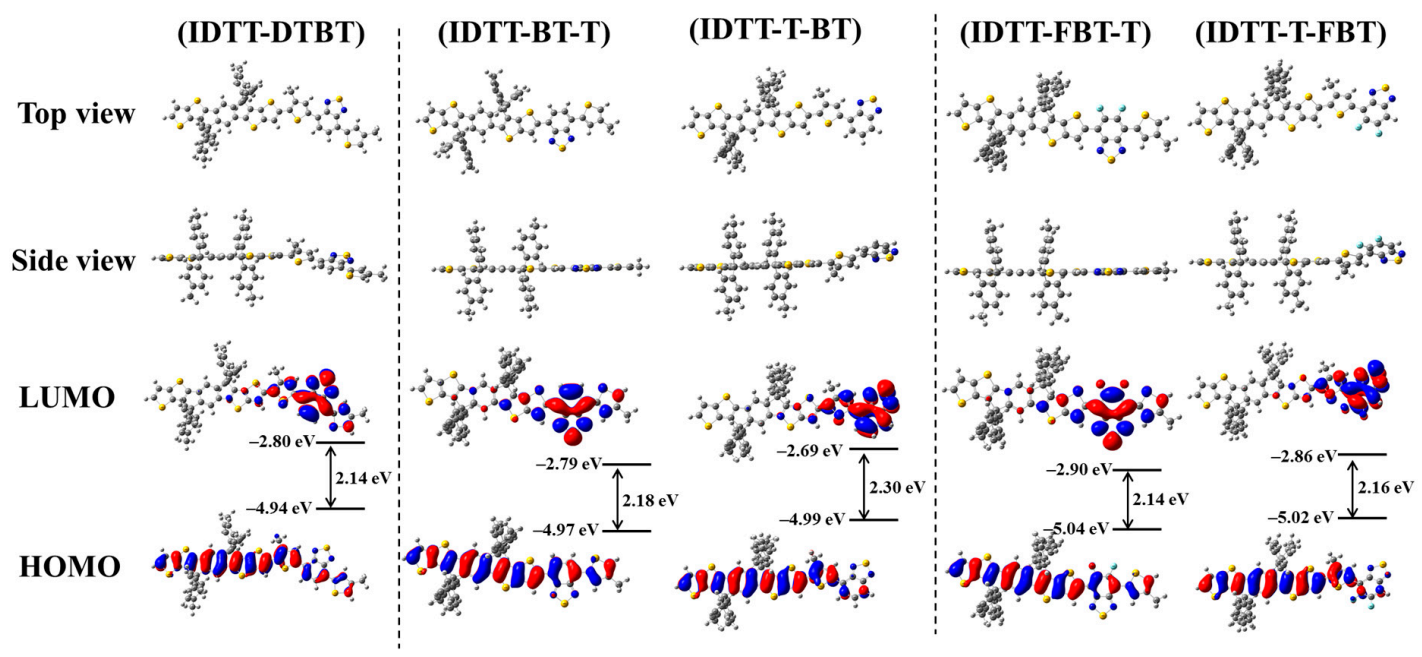

Figure 6. The optimized geometries and molecular orbital surfaces of the HOMO and LUMO for the unimer model compound of the polymers PIDTT-DTBT, PIDTT-TBT, and PIDTT-TFBT.

Table 2. Dihedral angles for the unimer models of PIDTT-DTBT, PIDTT-TBT, and PIDTT-TFBT obtained at from DFT at the B3LYP/6-31G* level.

\begin{tabular}{|c|c|c|c|}
\hline Polymer & Model Compound & Molecular Structure & Dihedral Angle (deg) \\
\hline PIDTT-DTBT & (IDTT-DTBT) & 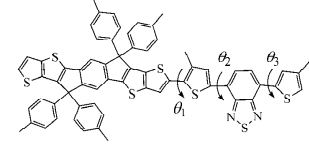 & $\begin{array}{l}\theta_{1}=-146.30 \\
\theta_{2}=-172.96 \\
\theta_{3}=-176.93\end{array}$ \\
\hline \multirow{2}{*}{ PIDTT-TBT } & (IDTT-BT-T) & 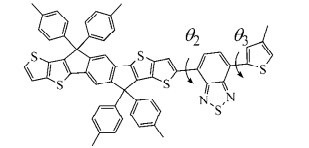 & $\begin{array}{l}\theta_{2}=179.77 \\
\theta_{3}=179.28\end{array}$ \\
\hline & (IDTT-T-BT) & 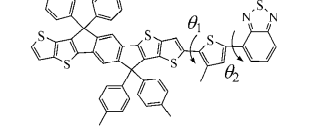 & $\begin{array}{c}\theta_{1}=146.33 \\
\theta_{2}=-170.71\end{array}$ \\
\hline \multirow{2}{*}{ PIDTT-TBT } & (IDTT-FBT-T) & 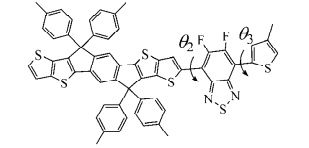 & $\begin{array}{l}\theta_{2}=179.94 \\
\theta_{3}=179.87\end{array}$ \\
\hline & (IDTT-T-FBT) & 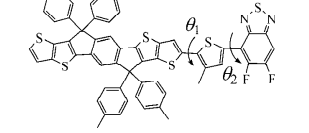 & $\begin{array}{c}\theta_{1}=147.93 \\
\theta_{2}=-177.82\end{array}$ \\
\hline
\end{tabular}


Since the good planarity in polymer backbone is helpful to promote closer $\pi-\pi$ stacking, higher charge transfer, and enlarged molecular conjugation so as to generate the lower band gap for harvesting more sunlight $[24,75]$. Thus, we further inspected the dihedral angles $\theta_{1}$ between IDTT unit and alkylthiophene bridge, $\theta_{2}$ and $\theta_{3}$ between alkylthiophene bridge and $\mathrm{BT}$ and/or moiety. According to the data of Table 2, in spite of position of the thiophene $\pi$-bridge in the polymer backbone, the backbone planarity was all improved, meanwhile, the fluorination further optimized the backbone planarity. Definitely, these variations concerning energy level and molecular planarity can well agree with the results measured in former $\mathrm{CV}$ and XRD analyses.

\subsection{Photovoltaic Properties}

In order to probe into the impact of reducing thiophene $\pi$-bridge and further fluorination in IDTT-based polymer backbone on the photovoltaic properties, the devices with the configuration of ITO/PEDOT:PSS/polymers:PCBM/PDINO/Al were fabricated. Note that the photoactive layers were prepared by spin-coating the solution involving the studied copolymers and $\mathrm{PC}_{61} \mathrm{BM}$ and/or $\mathrm{PC}_{71} \mathrm{BM}$, and the ultrathin interfacial layer (spinning from $1 \mathrm{mg} \mathrm{L}^{-1}$ PDINO solution in methanol) was utilized as cathode-modified interlayer [13]. The photovoltaic performance was optimized by the following processing, screening out the $\mathrm{D} / \mathrm{A}$ ratio, utilizing the 1,8-diiodioctane (DIO) processing additive and substituting $\mathrm{PC}_{61} \mathrm{BM}$ with $\mathrm{PC}_{71} \mathrm{BM}$. These device fabrication processes are listed in Supporting Information (Figures S11 and S12 and Table S2 in Supplementary Materials) in detail. After screening the D/A ratios, 1:1, 1:2 to 1:3, it was exhibited that the optimal D/A ratio for PIDTT-DTBT, PIDTT-TBT, and PIDTT-TFBT was 1:2, as shown in Figure S11. Seen from Table S2, the control device based on PIDTT-DTBT exhibited the best PCE of $2.05 \%$, with a $V_{\mathrm{OC}}$ of $0.81 \mathrm{~V}$, a $J_{\mathrm{SC}}$ of $5.51 \mathrm{~mA}$ $\mathrm{cm}^{-2}$, and a $F F$ of $45.67 \%$, and PIDTT-TBT-based device showed an enhanced PCE of $4.48 \%$, with the collaboratively enhanced $V_{\mathrm{OC}}$ of $0.87 \mathrm{~V}, J_{\mathrm{SC}}$ of $10.44 \mathrm{~mA} \mathrm{~cm}^{-2}$ and $F F$ of $49.30 \%$; however, further fluorinated PIDTT-TFBT-based device showed an inferior PCE of $2.60 \%$, with both decreased $J_{S C}$ of $5.63 \mathrm{~mA} \mathrm{~cm}^{-2}$ and $F F$ of $49.08 \%$ and a further elevated $V_{\mathrm{OC}}$ of $0.94 \mathrm{~V}$. Meanwhile, the corresponding external quantum efficiency (EQE) curves corroborated the changes relative to $J_{\mathrm{SC}}$, as depicted in Figure S11.

Since processing solvent additive with high boiling point was conducive to forming more ordered and nano-scaled bicontinuous interpenetration network structure which can improve the dissociation of light-induced exciton into the free charge carriers at the D/A interface and accelerate the transport of free charge carriers $[85,86]$. Hence, following that, we selected the $3 \% \mathrm{DIO}(\mathrm{DIO} / \mathrm{CB}, \mathrm{V} / \mathrm{V})$ as a solvent additive to proceed to optimize the device performance, as illustrated in Figure S12 (in Supplementary Materials). Unfortunately, a 14.6\% deterioration of PCE (from 2.05 to $1.75 \%$ ) in the control polymer PIDTT-DTBT-based device was found, mainly originating from the $18.2 \%$ decline in FF (from 45.67 to $437.37 \%$ ) the even though the slight increases of $V_{\mathrm{OC}}$ (from 0.81 to $0.84 \mathrm{~V}$ ) and $J_{\mathrm{SC}}$ (from 5.51 to $5.57 \mathrm{~mA}$ $\mathrm{cm}^{-2}$ ). As for PIDTT-TBT-based devices, it was exhibited that the $10.3 \%$ elevation in PCE (from 4.48 to $4.94 \%$ ) was observed, chiefly benefiting from the $7.8 \%$ enhancement in FF (from 49.30 to $53.14 \%$ ) even if $V_{\mathrm{OC}}$ and $J_{\mathrm{SC}}$ kept relatively constant. A $12.3 \%$ increase in PCE (from 2.60 to $2.92 \%$ ) was inspected in the further fluorination of PIDTT-TFBT-based device, primarily benefiting from slightly enhancements of $5.9 \%$ in $J_{\mathrm{SC}}$ (from 5.63 to $5.95 \mathrm{~mA} \mathrm{~cm}^{-2}$ ) and $5.0 \%$ in $F F(49.08$ to $51.54 \%$ ) under the condition of the almost unchanged $V_{\mathrm{OC}}$. Apparently, positive effect in PIDTT-TBT and fluorinated PIDTT-TFBT but negative impact in the reference material PIDTT-DTBT on the photovoltaic performance were observed.

On account of $\mathrm{PC}_{71} \mathrm{BM}$ possessing relatively higher absorption coefficient and broader absorption band than those of $\mathrm{PC}_{61} \mathrm{BM}$, herein $\mathrm{PC}_{71} \mathrm{BM}$ was applied to replace $\mathrm{PC}_{61} \mathrm{BM}$ for further enhancing the PCE [87], as displayed in Figure S12. As shown in Table S2, the enhancement of 10.9\% (from 1.75 to $1.84 \%$ ) for PCE in PIDTT-DTBT-based device was achieved, primarily originating from $10.1 \%$ increase in FF (from 37.37 to $41.15 \%$ ). Inspiringly, the remarkable 18.2\% improvement of PCE for PIDTT-TBT was obtained, mainly benefiting from concurrently upshifted by $5.1 \% J_{\mathrm{SC}}$ (from 10.54 to $11.08 \mathrm{~mA}$ $\mathrm{cm}^{-2}$ ) and $12.2 \%$ FF (from 53.14 to $559.60 \%$ ) but the stable $V_{\mathrm{OC}}$. However, as for the fluorinated 
PIDTT-TFBT-based device, a $8.6 \%$ decline in PCE (from 2.92 to $2.67 \%$ ) was obtained, mostly limited by $8.6 \%$ drop in $J_{\mathrm{SC}}$ (from 5.95 to $5.44 \mathrm{~mA} \mathrm{~cm}^{-2}$ ) but constant $V_{\mathrm{OC}}$ and almost unvaried $F F$. It was noted that these relevant $J_{\mathrm{SC}}$ variations were also confirmed by corresponding EQE curves in Figure S12.

With the assistance of $\mathrm{D} / \mathrm{A}$ ratio screening, DIO additive and utilizing $\mathrm{PC}_{71} \mathrm{BM}$ to replace $\mathrm{PC}_{61} \mathrm{BM}$, the optimal $J-V$ characteristics and corresponding EQE spectra were elucidated in Figure 7. Seen from Table 3, for as much as the moderate electron-donating IDTT and strong electron-withdrawing BT subunits was selected to construct the polymer backbone, these yielded photovoltaic devices exhibited relatively higher $V_{\mathrm{OC}}$ ranging from 0.81 to $0.95 \mathrm{~V}$. Meanwhile, the gradual increasing tendency of $V_{\mathrm{OC}}$ (from 0.81 to 0.88 then to $0.95 \mathrm{~V}$ ) in the order of PIDTT-DTBT, PIDTT-TBT, and PIDTT-TFBT was in accordance with the above deepened $E_{\mathrm{HOMO}}$ predicted by DFT and CV tests [24]. We can see that the best PCE was remarkably increased from 2.05 to $5.84 \%$ after reducing the thiophene $\pi$-bridge, chiefly benefiting from collaborative $8.6 \%$ increase in $V_{\mathrm{OC}}$ (from 0.81 to $0.88 \mathrm{~V}$ ), $101 \%$ enhancement in $J_{\mathrm{SC}}$ (from 5.51 to $11.08 \mathrm{~mA} \mathrm{~cm}^{-2}$ ), and $30.5 \%$ elevation in $F F$ (from 45.67 to $59.60 \%$ ). Conversely, $50 \%$ downshifted PCE (from 5.84 to $2.92 \%$ ) was found after further fluorination, which was mainly limited by $46.4 \%$ decrease in $J_{\mathrm{SC}}$ (from 11.08 to $5.95 \mathrm{~mA} \mathrm{~cm}^{-2}$ ) and $13.52 \%$ drop in $F F$ (from 59.60 to $51.54 \%$ ) even if the $V_{\mathrm{OC}}$ increased by $18 \%$ (from 0.88 to $0.95 \mathrm{~V}$ ). Theses $J_{\mathrm{SC}}$ variations were also verified by the corresponding EQE spectra (Figure $7 \mathrm{~b}$ ). Another point that needs to be emphasized is that the integrated $J_{\mathrm{SC}}$ values in terms of EQE curves were estimated to be $5.45,11.00$, and $5.80 \mathrm{~mA} \mathrm{~cm}^{-2}$ for the optimal PIDTT-DTBT:PC ${ }_{61}$ BM, PIDTT-TBT:PC ${ }_{71} B M$, and PIDTT-TFBT:PC ${ }_{61} B M$, respectively, indicating there existed the tolerated error $(<5 \%)$ with respect to $J_{\mathrm{SC}}$ values measured from $J-V$ curves, demonstrating these $J_{\mathrm{SC}}$ values were reliable. Furthermore, the first enhanced then decreased change trend for $F F$ was also confirmed by the first increased then decreased shunt resistance $\left(R_{\mathrm{SH}}\right)$ (from 565 to 604 then to $536 \Omega \mathrm{m}^{2}$ ) and first decreased then increased series resistance $\left(R_{\mathrm{S}}\right)$ (from 43.4 to 7.7 then to $14.9 \Omega \mathrm{m}^{2}$ ) when reducing the thiophene $\pi$-bridge and the further fluorination.
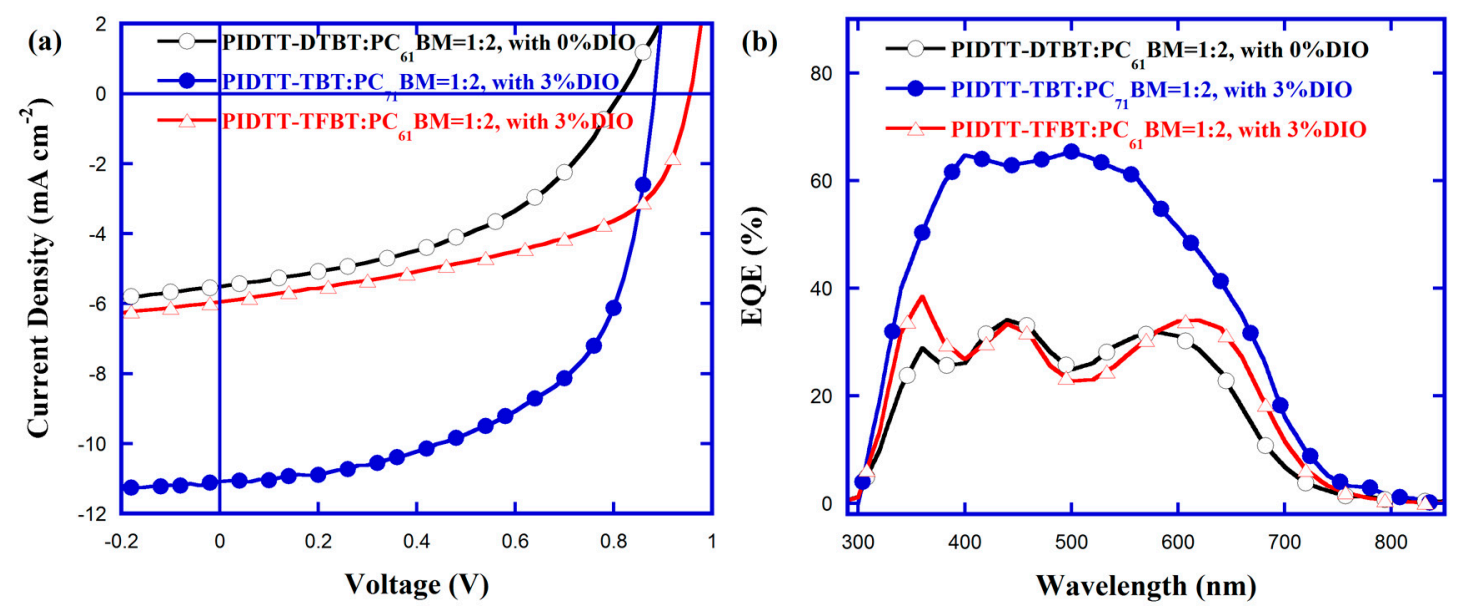

Figure 7. The optimal $J$ - $V$ curves (a) and the EQE spectra (b) of the polymer solar cells (PSCs) based on the resultant polymers.

Table 3. The optimized PV parameters of PSCs based on the studied copolymers.

\begin{tabular}{|c|c|c|c|c|c|c|c|}
\hline Active Layer & Ratios/DIO & $V_{\text {OC }}(\mathrm{V})$ & $\begin{array}{c}J \mathrm{SC} \\
\left(\mathrm{mA} \mathrm{cm}^{-2}\right)^{\mathrm{a}} \\
\end{array}$ & $\begin{array}{l}F F \\
(\%)\end{array}$ & $\begin{array}{l}\text { PCE } \\
(\%)\end{array}$ & $\begin{array}{c}R_{\mathrm{SH}} \\
\left(\Omega \mathrm{m}^{2}\right)^{b}\end{array}$ & $\begin{array}{c}R_{S} \\
\left(\Omega \mathrm{m}^{2}\right)^{b}\end{array}$ \\
\hline PIDTT-DTBT/PC 61 BM (1:2) & $(1: 2) / 0 \%$ & 0.81 & $5.51(5.45)$ & 45.67 & 2.05 & 565 & 43.4 \\
\hline PIDTT-TBT/PC 71 BM & $(1: 2) / 3 \%$ & 0.88 & $11.08(11.00)$ & 59.60 & 5.84 & 604 & 7.7 \\
\hline PIDTT-TFBT/PC ${ }_{61} \mathrm{BM}(1: 2)$ & $(1: 2) / 3 \%$ & 0.95 & $5.95(5.80)$ & 51.54 & 2.92 & 536 & 14.9 \\
\hline
\end{tabular}

${ }^{a}$ The values in the parentheses are the integrated currents obtained from the EQE curves; ${ }^{b}$ Shunt resistance $\left(R_{\mathrm{SH}}\right)$ and series resistance $\left(R_{\mathrm{S}}\right)$ are deduced from the inverse slope at $V=0$ and $V=V_{\mathrm{OC}}$ in the $J-V$ curves under illumination. 


\subsection{Charge Mobilities}

In order to find the reason why reducing thiophene $\pi$-bridge and further fluorination in IDTT-based polymer backbone produced different impact on device performance, the vertical hole and electron transport properties were examined by hole-only and electron-only devices with the corresponding device configurations of ITO/PEDOT:PSS/blend/ $\mathrm{MoO}_{3} / \mathrm{Ag}$ and ITO/ZnO/blend/ $/ \mathrm{MoO}_{3} / \mathrm{Al}$, respectively. The prepared photoactive layer films were fabricated under the same conditions with their best PSCs. These charge mobilities were calculated according to SCLC method which can be described by the equation $J=\frac{9}{8} \varepsilon_{0} \varepsilon_{\mathrm{r}} \mu_{\mathrm{h}} \frac{V^{2}}{L^{3}}$ [76]. Note that these thickness values of resultant photoactive layer blend films for PIDTT-DTBT, PIDTT-TBT, and PIDTT-TFBT were 98, 100, and $105 \mathrm{~nm}$ for hole-only devices and 115, 118, and $100 \mathrm{~nm}$ for electron-only devices (Tables S3 and S4 in Supplementary Materials), respectively. The $J-V$ curves under dark are presented in Figure S13 (in Supplementary Materials) and the corresponding fitting $J^{1 / 2}-V$ curves for the photoactive layer films are shown in Figure 8. It was observed that the values for hole-mobility $\left(\mu_{\mathrm{h}}\right)$, electron-mobility $\left(\mu_{\mathrm{e}}\right)$, and $\mu_{\mathrm{h}} / \mu_{\mathrm{e}}$ ratio were $1.78 \times 10^{-4}, 8.56 \times 10^{-7} \mathrm{~cm}^{2} \mathrm{~V}^{-1} \mathrm{~s}^{-1}$, and 2074 for PIDTT-DTBT, $7.67 \times 10^{-4}, 4.07 \times 10^{-7} \mathrm{~cm}^{2} \mathrm{~V}^{-1} \mathrm{~s}^{-1}$, and 1884 for PIDTT-TBT, and $5.29 \times 10^{-4}, 1.77 \times 10^{-6} \mathrm{~cm}^{2} \mathrm{~V}^{-1} \mathrm{~s}^{-1}$, and 299 for PIDTT-TBT (Table 4), respectively. Apparently, the hole-mobility showed a first increased then decreased trend, and the electron-mobility exhibited a gradually increased tendency as well as $\mu_{\mathrm{h}} / \mu_{\mathrm{e}}$ exhibited a decreased tendency after reducing the thiophene $\pi$-bridge in PIDTT-TBT and further fluorinating in PIDTT-TFBT compared to PIDTT-DTBT. These observed increased $\mu_{\mathrm{h}}, \mu_{\mathrm{e}}$ and more balanced $\mu_{\mathrm{h}} / \mu_{\mathrm{e}}$ values can in part account for the $30.5 \%$ increased $F F$ and $101 \%$ elevated $J_{\mathrm{SC}}$ after reducing the thiophene $\pi$-bridge in PIDTT-TBT [88]. Moreover, the decreased $\mu_{\mathrm{h}}$ after further fluorination in PIDTT-TFBT can explain the reason to some extent why the $13.52 \%$ deteriorated $F F$ and $46.39 \%$ decreased $J_{S C}$ were observed, which could be further supported by the latter oversized aggregation seen from AFM and TEM analyses.
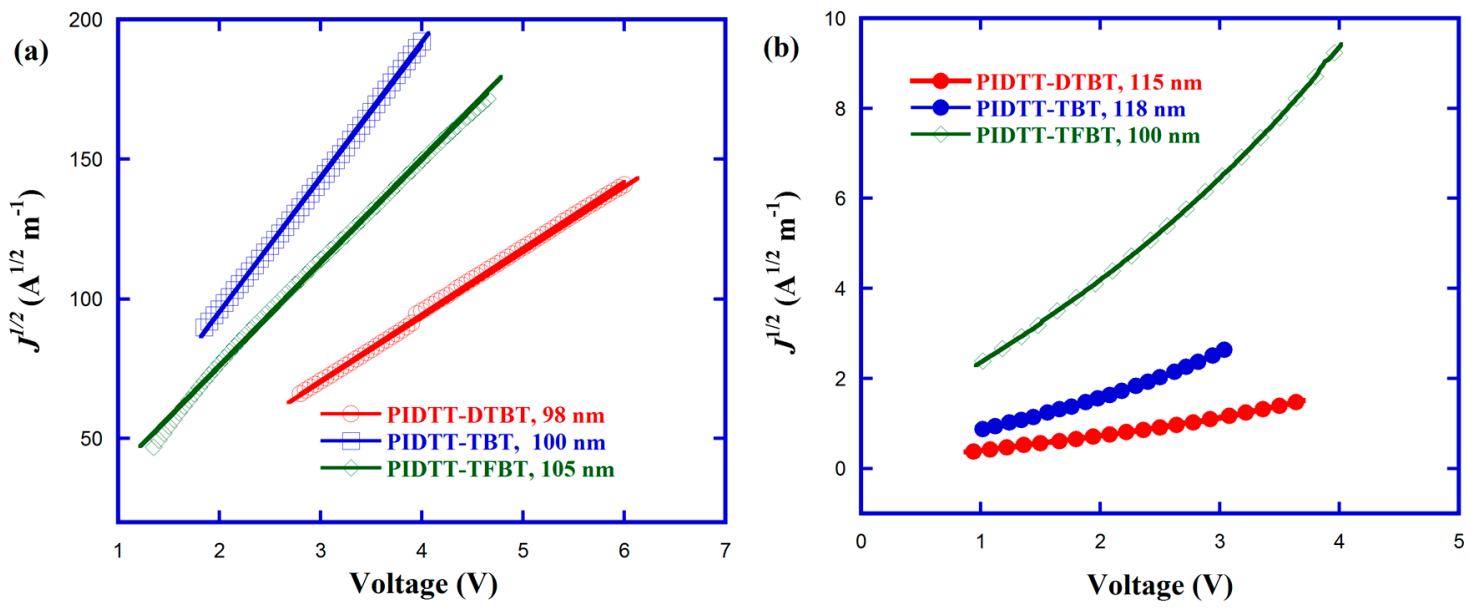

Figure 8. Fitting $J^{1 / 2}-V$ characteristics of hole-only (a) and electron-only (b) devices based on the studied CPs.

Table 4. Mobility of the studied polymers PIDTT-DTBT, PIDTT-TBT, and PIDTT-TFBT.

\begin{tabular}{cccc}
\hline Active Layer & $\mu_{\mathbf{h}}{ }^{\mathbf{a}}\left(\mathbf{c m}^{\mathbf{2}} \mathbf{V}^{-\mathbf{1}} \mathbf{s}^{-\mathbf{1}}\right)$ & $\mu_{\mathrm{e}}{ }^{\mathbf{b}}\left(\mathbf{c m}^{\mathbf{2}} \mathbf{V}^{-\mathbf{1}} \mathbf{s}^{-\mathbf{1}}\right)$ & $\mu_{\mathrm{h}} / \mu_{\mathrm{e}}$ \\
\hline PIDTT-DTBT:PC $_{61} \mathrm{BM}=1: 2$ & $1.78 \times 10^{-4}$ & $8.56 \times 10^{-7}$ & 2074 \\
PIDTT-TBT:PC $_{71} \mathrm{BM}=1: 2$ & $7.67 \times 10^{-4}$ & $4.07 \times 10^{-7}$ & 1884 \\
PIDTT-TFBT:PC $_{61} \mathrm{BM}=1: 2$ & $5.29 \times 10^{-4}$ & $1.77 \times 10^{-8}$ & 299 \\
\hline
\end{tabular}

a The hole-only devices with the structure of ITO/PEDOT:PSS/polymer:PCBM/ $/ \mathrm{MoO}_{3} / \mathrm{Ag}$; ${ }^{\text {b }}$ The electron-only devices with the structure of ITO/ZnO/polymer:PCBM/PFN/Al. 


\subsection{Film Morphology}

It is known to all that photovoltaic performance are strongly depended on the morphology of the photoactive layer in BHJ PSCs [21,86,89-91]. Consequently, in order to deeply make a thorough inquiry into the causes why reducing the thiophene $\pi$-bridge in PIDTT-TBT had a positive impact on PCE but the further fluorination had a negative effect on PCE in PIDTT-TFBT, the morphologies of the photoactive layer films prepared under exactly similar condition with those of optimal device were examined by AFM in a surface area of $5 \times 5 \mu \mathrm{m}$. As seen from Figure 9, it was exhibited that the both PIDTT-DTBT and PIDTT-TBT-based blend films had very similar surface morphology with the nearest root-mean-square (RMS) roughness of 0.759 and $0.587 \mathrm{~nm}$, respectively, and the fluorinated PIDTT-TFBT-based film displayed greatly increased RMS value of $2.071 \mathrm{~nm}$; these vibrations as a whole were in accordance with the solid aggregation trend observed in the preceding XRD analysis. Furthermore, we utilized the TEM to further examine the in-depth morphology information of the photoactive layers, as depicted in Figure 10. We can see that when reducing thiophene $\pi$-bridge in PIDTT-TBT exhibited the slightly optimized phase separation compared with the control polymer PIDTT-DTBT, in the meantime, further fluorination in PIDTT-TFBT exhibited oversized aggregation restricting the effective exciton diffusion and decreasing the exciton dissociation into the free charges via reducing D/A interfacial areas as well as enhancing the charge recombination, which would lead to a detrimental $F F$ and $J_{\mathrm{SC}}$ [21]. These morphology information can in part account for the improved photovoltaic performance in PIDTT-TBT-based device but deteriorated performance after further fluorination in PIDTT-TFBT were acquired.
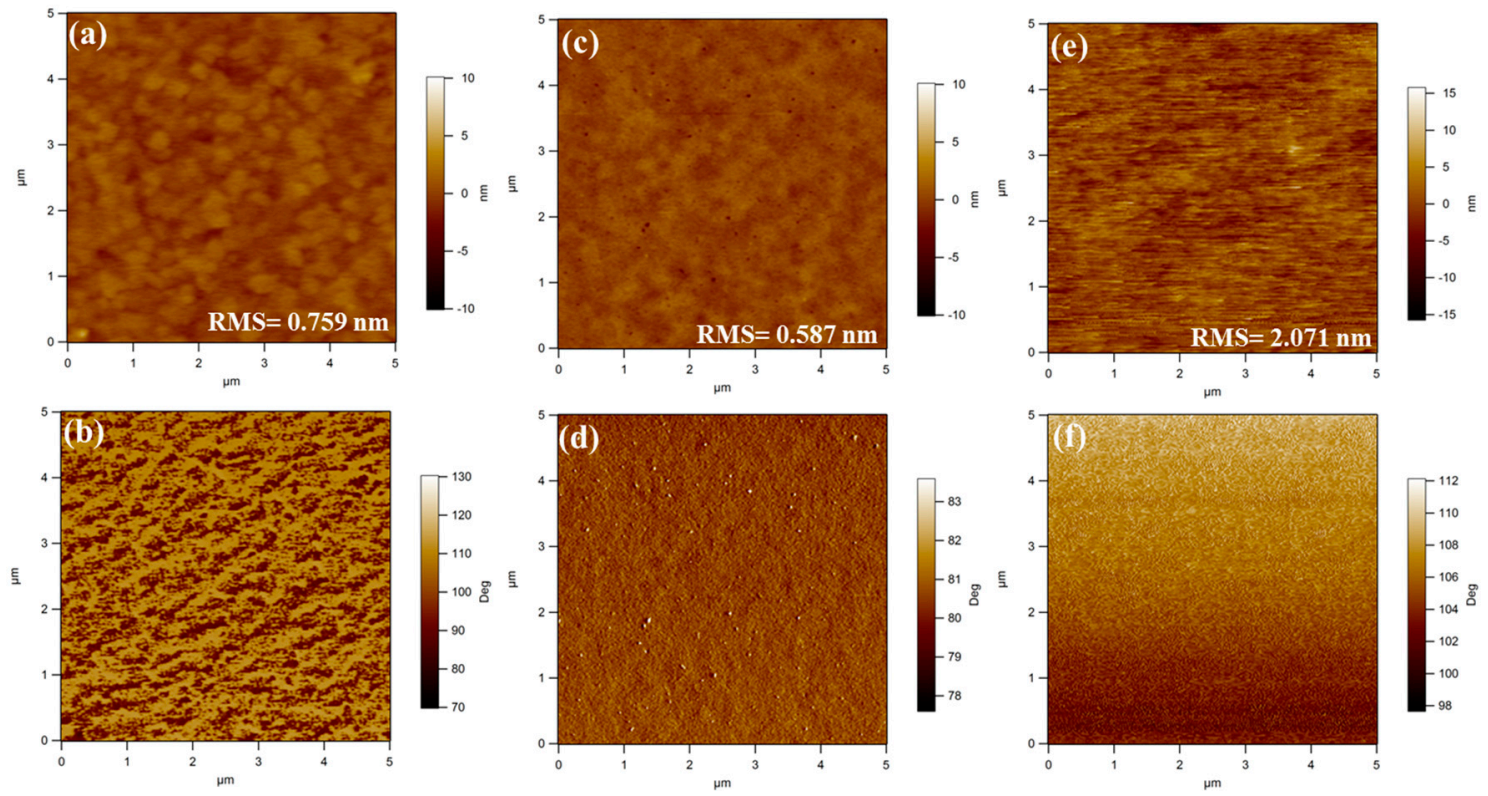

Figure 9. Tapping atomic force microscopy (AFM) height (top) and phase (bottom) images for photoactive layers of PIDTT-DTBT/PC 61 BM (1:2, $0 \%$ DIO, (a,b)), PIDTT-TBT/PC 71 BM (1:2, 3\%DIO, (c,d)) and PIDTT-TFBT/PC ${ }_{61} \mathrm{BM}(1: 2,3 \% \mathrm{DIO},(\mathbf{e}, \mathbf{f}))$. Image size: $5 \mu \mathrm{m} \times 5 \mu \mathrm{m}$. 

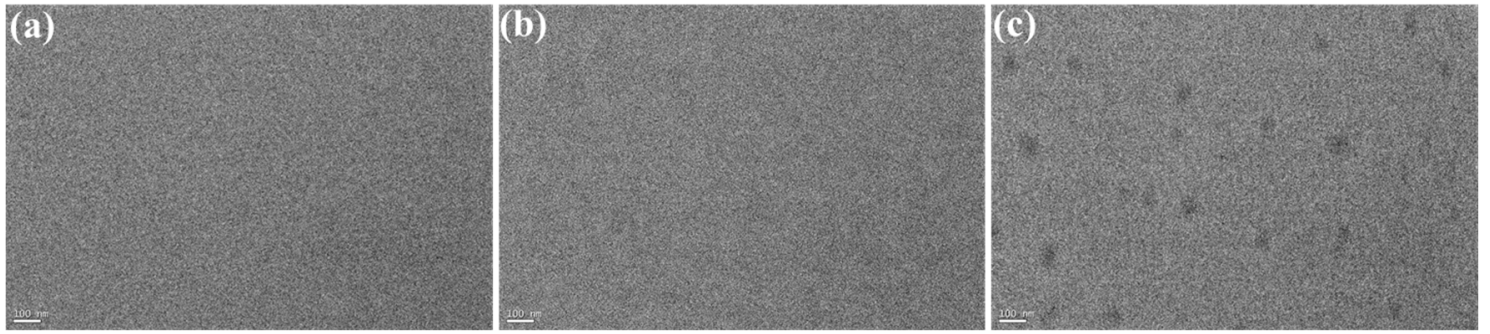

Figure 10. Transmission electron microscopy (TEM) bright field images of photoactive layers for PIDTT-DTBT/PC 61 BM (1:2, 3\%DIO, (a)), PIDTT-TBT/PC 71 BM (1:2, 3\%DIO, (b)) and PIDTT-TFBT/ $\mathrm{PC}_{61} \mathrm{BM}(1: 1.5,3 \% \mathrm{DIO},(\mathrm{c}))$. The scale bar of TEM images is $100 \mathrm{~nm}$.

\section{Conclusions}

To conclude, two IDTT-based random CPs, PIDTT-TBT and PIDTT-TFBT as well as the alternating copolymer PIDTT-DTBT as control material, were designed to study the influence of reducing thiophene $\pi$-bridge and further fluorination on photostability and photovoltaic performance. Because of selecting the moderate electron-donating IDTT and strong electron-withdrawing BT to construct the polymer backbone, the wide bandgap of $1.76 \sim 1.79 \mathrm{eV}$, lowlying $E_{\mathrm{HOMO}}$ ranging from -5.28 to $-5.43 \mathrm{eV}$ and excellent photostability were achieved. It was exhibited that the broadened and increased absorption, deepened $E_{\mathrm{HOMO}}$, improved molecular planarity, and thus enhanced film aggregation, but tiny impact on aggregation in CB solution and photostability were observed when PIDTT-DTBT was replaced with PIDTT-TBT and PIDTT-TFBT successively. The best photovoltaic tests disclosed that, PIDTT-TBT-based device yielded $185 \%$ increased PCE from 2.05 to $5.84 \%$ benefiting from simultaneously elevated $V_{\mathrm{OC}}$ of $0.88 \mathrm{~V}$, $J_{\mathrm{SC}}$ of $11.08 \mathrm{~mA} \mathrm{~cm}^{-2}$, and $F F$ of $59.60 \%$ compared to the counterpart, and this improvement was chiefly profited by the broadened and increased absorption, deepened $E_{\mathrm{HOMO}}$, raised $\mu_{\mathrm{h}}$, and more balanced $\mu_{\mathrm{h}} / \mu_{\mathrm{e}}$, and slightly optimized morphology of photoactive layer. Conversely, the $50 \%$ reduced PCE was observed after further fluorination limited by the minimized $J_{S C}$ and $F F$, mainly limited by undesired morphology for photoactive layer film as a result of strong aggregation despite of the enlarged $V_{\mathrm{OC}}$. This work suggested tuning the $\pi$-bridge in polymer backbone was an easy-to-implement and effectual tactic with a view to enhancing the photovoltaic property.

Supplementary Materials: Detailed experimental procedures and additional characterization data are available online at http://www.mdpi.com/2073-4360/12/2/368/s1. Scheme S1: Synthesis of dibromide DTBTBr $2, \mathrm{TBTBr}_{2}$, and $\mathrm{TFBTBr}_{2}$. Figure S1: ${ }^{1} \mathrm{H}$ NMR spectrum of $\mathrm{DTBTBr}_{2}$ in $\mathrm{CDCl}_{3}$. Figure $\mathrm{S} 2:{ }^{1} \mathrm{H} \mathrm{NMR}$ spectrum of $\mathrm{TBTBr}$ in $\mathrm{CDCl}_{3}$. Figure S3: ${ }^{1} \mathrm{H}$ NMR spectrum of $\mathrm{TBTBr}_{2}$ in $\mathrm{CDCl}_{3}$. Figure S4: ${ }^{1} \mathrm{H} \mathrm{NMR}$ spectrum of $\mathrm{TFBTBr}$ in $\mathrm{CDCl}_{3}$. Figure S5: ${ }^{1} \mathrm{H}$ NMR spectrum of $\mathrm{TFBTBr}_{2}$ in $\mathrm{CDCl}_{3}$. Figure $\mathrm{S6}:{ }^{1} \mathrm{H} \mathrm{NMR}$ spectrum of PIDTT-DTBT in $\mathrm{CDCl}_{3}$. Figure S7: ${ }^{1} \mathrm{H}$ NMR spectrum of PIDTT-TBT in $\mathrm{CDCl}_{3}$. Figure S8: ${ }^{1} \mathrm{H}$ NMR spectrum of PIDTT-TFBT in $\mathrm{CDCl}_{3}$. Figure S9: TGA curves of PIDTT-DTBT, PIDTT-TBT, and PIDTT-TFBT. Figure S10: UV-vis absorption spectra changes after illumination of PIDTT-DTBT (a), PIDTT-TBT (b), and PIDTT-TFBT (c) in CB solution and a summary of light absorption intensity changes at the peak of each polymer as a function of light-soaking time (d). Figure S11: The J-V curves of the studied copolymers with different weight ratio to $\mathrm{PC}_{61} \mathrm{BM}$ and $\mathrm{EQE}$ spectra of corresponding PSCs. Figure S12: The J-V curves of polymers without and with $3 \% \mathrm{DIO}, \mathrm{PC}_{61} \mathrm{BM}$ replacing with $\mathrm{PC}_{71} \mathrm{BM}_{\text {and }}$ EQE spectra of corresponding PSCs. Figure S13: J-V curves of hole-only (a) and electron-only (b) devices for the studied copolymers. Table S1: Yields, GPC data, thermal properties for the studied copolymers. Table S2: The photovoltaic performance of the PSCs devices under varied fabrication processes. Table S3: Hole mobilities of the optimized devices measured by SCLC model. Table S4: Electron mobilities of the optimized device measured by the SCLC model.

Author Contributions: L.A. and Y.H. prepared the conjugated polymers and finished the characterization. J.T. wrote the paper, designed the experiments, analyzed the data, and discussed the results. Z.L., J.L., and C.Y. contributed to the measurements of solar cell. X.W. finished the DFT calculation. All authors have read and agreed to the published version of the manuscript.

Funding: We are deeply grateful to the Fundamental Research Funds for the Central Universities (31920190156), Lanzhou Jiaotong University-Tianjin University Joint Innovation Fund Project Funding (2019056), National Nature Science Foundation of China (61964010, 51602139), and Excellent Team of Scientific Research in Lanzhou Jiaotong University (201705) for financial support. This work was supported by the Open Fund of the State Key Laboratory 
of Luminescent Materials and Devices (South China University of Technology). We also express our thanks to Instrument Analysis Center of LZJTU for the associated testing support.

Conflicts of Interest: The authors declare no conflict of interest.

\section{References}

1. Cheng, P.; Zhan, X. Stability of organic solar cells: Challenges and strategies. Chem. Soc. Rev. 2016, 45, 2544-2582. [CrossRef] [PubMed]

2. Lv, J.; Feng, Y.; Fu, J.; Gao, J.; Singh, R.; Kumar, M.; Kim, M.; Tang, H.; Lu, S.; Zhang, W.; et al. Energetic disorder and activation energy in efficient ternary organic solar cells with nonfullerene acceptor Eh-IDTBR as the third component. Sol. RRL 2019, 1900403. [CrossRef]

3. Li, Y. Molecular design of photovoltaic materials for polymer solar cells: Toward suitable electronic energy levels and broad absorption. Acc. Chem. Res. 2012, 45, 723-733. [CrossRef] [PubMed]

4. Liu, Y.; Zhao, J.; Li, Z.; Mu, C.; Ma, W.; Hu, H.; Jiang, K.; Lin, H.; Ade, H.; Yan, H. Aggregation and morphology control enables multiple cases of high-efficiency polymer solar cells. Nat. Commun. 2014, 5, 5293. [CrossRef] [PubMed]

5. Li, J.; Liang, Z.; Wang, Y.; Li, H.; Tong, J.; Bao, X.; Xia, Y. Enhanced efficiency of polymer solar cells through synergistic optimization of mobility and tuning donor alloys by adding high-mobility conjugated polymers. J. Mater. Chem. C 2018, 6, 11015-11022. [CrossRef]

6. Wang, X.; Dou, K.; Shahid, B.; Liu, Z.; Li, Y.; Sun, M.; Zheng, N.; Bao, X.; Yang, R. Terpolymer strategy toward high-efficiency polymer solar cells: Integrating symmetric benzodithiophene and asymmetrical thieno[2,3-f]benzofuran segments. Chem. Mater. 2019, 31, 6163-6173. [CrossRef]

7. Wang, X.; Du, Z.; Dou, K.; Jiang, H.; Gao, C.; Han, L.; Yang, R. A maverick asymmetrical backbone with distinct flanked twist angles modulating the molecular aggregation and crystallinity for high performance nonfullerene solar cells. Adv. Energy Mater. 2019, 9, 1802530. [CrossRef]

8. Zhao, J.; Li, Y.; Yang, G.; Jiang, K.; Lin, H.; Ade, H.; Ma, W.; Yan, H. Efficient organic solar cells processed from hydrocarbon solvents. Nat. Energy 2016, 1, 15027. [CrossRef]

9. Yuan, J.; Zhang, Y.; Zhou, L.; Zhang, G.; Yip, H.-L.; Lau, T.-K.; Lu, X.; Zhu, C.; Peng, H.; Johnson, P.A.; et al. Single-junction organic solar cell with over $15 \%$ efficiency using fused-ring acceptor with electron-deficient core. Joule 2019, 3, 1140-1151. [CrossRef]

10. Aldrich, T.J.; Matta, M.; Zhu, W.; Swick, S.M.; Stern, C.L.; Schatz, G.C.; Facchetti, A.; Melkonyan, F.S.; Marks, T.J. Fluorination effects on indacenodithienothiophene acceptor packing and electronic structure, end-group redistribution, and solar cell photovoltaic response. J. Am. Chem. Soc. 2019, 141, 3274-3287. [CrossRef]

11. Li, J.; Wang, Y.; Liang, Z.; Wang, N.; Tong, J.; Yang, C.; Bao, X.; Xia, Y. Enhanced organic photovoltaic performance through modulating vertical composition distribution and promoting crystallinity of the photoactive layer by diphenyl sulfide additives. ACS Appl. Mater. Interfaces 2019, 11, 7022-7029. [CrossRef] [PubMed]

12. Li, S.; Zhan, L.; Sun, C.; Zhu, H.; Zhou, G.; Yang, W.; Shi, M.; Li, C.-Z.; Hou, J.; Li, Y.; et al. Highly efficient fullerene-free organic solar cells operate at near zero highest occupied molecular orbital offsets. J. Am. Chem. Soc. 2019, 141, 3073-3082. [CrossRef] [PubMed]

13. Liang, Z.; Tong, J.; Li, H.; Wang, Y.; Wang, N.; Li, J.; Yang, C.; Xia, Y. The comprehensive utilization of the synergistic effect of fullerene and non-fullerene acceptors to achieve highly efficient polymer solar cells. J. Mater. Chem. A 2019, 7, 15841-15850. [CrossRef]

14. Stoltzfus, D.M.; Donaghey, J.E.; Armin, A.; Shaw, P.E.; Burn, P.L.; Meredith, P. Charge generation pathways in organic solar cells: Assessing the contribution from the electron acceptor. Chem. Rev. 2016, 116, 12920-12955. [CrossRef]

15. Li, X.; Liang, Z.; Wang, H.; Qiao, S.; Liu, Z.; Jiang, H.; Chen, W.; Yang, R. Fluorinated D1(0.5)-A-D2(0.5)-A model terpolymer: Ultrafast charge separation kinetics and electron transfer at fluorinated D/A interface for power conversion. J. Mater. Chem. A 2019. [CrossRef]

16. Wang, Y.; Liang, Z.; Qin, J.; Tong, J.; Guo, P.; Cao, X.; Li, J.; Xia, Y. An alcohol-soluble polymer electron transport layer based on perylene diimide derivatives for polymer solar cells. IEEE J. Photovolt. 2019, 9, 1678-1685. [CrossRef] 
17. Yao, H.; Cui, Y.; Qian, D.; Ponseca, C.S., Jr.; Honarfar, A.; Xu, Y.; Xin, Z.; Chen, J.; Hong, L.; Gao, B.; et al. $14.7 \%$ Efficiency organic photovoltaic cells enabled by active materials with a large electrostatic potential difference. J. Am. Chem. Soc. 2019, 141, 7743-7750. [CrossRef]

18. Zhang, X.; Wang, F.; Tong, J.; Zhang, M.; Guo, P.; Li, J.; Xia, Y.; Wang, C.; Wu, H. Systematically investigating the influence of inserting alkylthiophene spacers on the aggregation, photo-stability and optoelectronic properties of copolymers from dithieno[2,3-d:2', $\left.3^{\prime}-d^{\prime}\right]$ benzo[1,2-b:4,5- $\left.b^{\prime}\right]$ dithiophene and benzothiadiazole derivatives. Polym. Chem. 2019, 10,972-982. [CrossRef]

19. Zhang, Z.-G.; Wang, J. Structures and properties of conjugated donor-acceptor copolymers for solar cell applications. J. Mater. Chem. 2012, 22, 4178-4187. [CrossRef]

20. Zhou, H.; Yang, L.; You, W. Rational design of high performance conjugated polymers for organic solar cells. Macromolecules 2012, 45, 607-632. [CrossRef]

21. Kim, T.; Lee, J.Y.; Heo, J.; Lim, B.; Kim, J.Y. Highly efficient polymer solar cells with a thienopyrroledione and benzodithiophene containing planar random copolymer. Polym. Chem. 2018, 9, 1216-1222. [CrossRef]

22. Bibi, S.; Jia, R.; Zhang, H.-X.; Bai, F.-Q. Effect of different topological structures (D- $\pi$-D and D- $\pi-A-\pi-D)$ on the optoelectronic properties of benzo[2,1-b:3,4- $\left.b^{\prime}\right]$ dithiophene based donor molecules toward organic solar cells. Sol. Energy 2019, 186, 311-322. [CrossRef]

23. Busireddy, M.R.; Chakali, M.; Reddy, G.R.; Chereddy, N.R.; Shanigaram, B.; Kotamarthi, B.; Sharma, G.D.; Rao, V.J. Influence of the backbone structure of the donor material and device processing conditions on the photovoltaic properties of small molecular BHJSCs. Sol. Energy 2019, 186, 84-93. [CrossRef]

24. Tong, J.; An, L.; Lv, J.; Guo, P.; Wang, X.; Yang, C.; Xia, Y. Enhanced photovoltaic performance in D- $\pi-A$ copolymers containing triisopropylsilylethynyl-substituted dithienobenzodithiophene by modulating the electron-deficient units. Polymers 2019, 11, 12. [CrossRef] [PubMed]

25. Wang, M.; Hu, X.; Liu, P.; Li, W.; Gong, X.; Huang, F.; Cao, Y. Donor-acceptor conjugated polymer based on naphtho[1,2-c:5,6-c'] bis[1,2,5]thiadiazole for high-performance polymer solar cells. J. Am. Chem. Soc. 2011, 133, 9638-9641. [CrossRef] [PubMed]

26. Guo, P.; Luo, G.; Su, Q.; Li, J.; Zhang, P.; Tong, J.; Yang, C.; Xia, Y.; Wu, H. Boosting up performance of inverted photovoltaic cells from bis(alkylthien-2-yl)dithieno[2,3-d:2' $\left.3^{\prime}-d^{\prime}\right]$ benzo[1,2- $\left.b: 4^{\prime}, 5^{\prime}-b^{\prime}\right]$ dithiophene-based copolymers by advantageous vertical phase separation. ACS Appl. Mater. Interfaces 2017, 9, 10937-10945. [CrossRef]

27. Zhang, M.; Guo, X.; Ma, W.; Ade, H.; Hou, J. A large-bandgap conjugated polymer for versatile photovoltaic applications with high performance. Adv. Mater. 2015, 27, 4655-4660. [CrossRef]

28. Zhao, W.; Li, S.; Yao, H.; Zhang, S.; Zhang, Y.; Yang, B.; Hou, J. Molecular optimization enables over 13\% efficiency in organic solar cells. J. Am. Chem. Soc. 2017, 139, 7148-7151. [CrossRef]

29. Bin, H.; Zhang, Z.-G.; Gao, L.; Chen, S.; Zhong, L.; Xue, L.; Yang, C.; Li, Y. Non-fullerene polymer solar cells based on alkylthio and fluorine substituted 2D-conjugated polymers reach 9.5\% efficiency. J. Am. Chem. Soc. 2016, 138, 4657-4664. [CrossRef]

30. Xu, T.; Yu, L. How to design low bandgap polymers for highly efficient organic solar cells. Mater. Today 2014, 17, 11-15. [CrossRef]

31. Huo, L.; Liu, T.; Sun, X.; Cai, Y.; Heeger, A.J.; Sun, Y. Single-junction organic solar cells based on a novel wide-bandgap polymer with efficiency of 9.7\%. Adv. Mater. 2015, 27, 2938-2944. [CrossRef] [PubMed]

32. Dong, Y.; Hu, X.; Duan, C.; Liu, P.; Liu, S.; Lan, L.; Chen, D.; Ying, L.; Su, S.; Gong, X.; et al. A series of new medium-bandgap conjugated polymers based on naphtho[1,2-c:5,6-c]bis(2-octyl[1,2,3]tri-azole) for high-performance polymer solar cells. Adv. Mater. 2013, 25, 3683-3688. [CrossRef] [PubMed]

33. Yang, J.; Uddin, M.A.; Tang, Y.; Wang, Y.; Wang, Y.; Su, H.; Gao, R.; Chen, Z.-K.; Dai, J.; Woo, H.Y.; et al. Quinoxaline-based wide band gap polymers for efficient nonfullerene organic solar cells with large open-circuit voltages. ACS Appl. Mater. Interfaces 2018, 102, 723235-723246. [CrossRef] [PubMed]

34. An, L.; Tong, J.; Yang, C.; Zhao, X.; Wang, X.; Xia, Y. Impact of alkyl side chain on photostability and optoelectronic properties of indacenodithieno[3,2- $b$ ] thiophene-alt-naphtho[1,2-c:5,6-c'] bis[1,2,5]thiadiazole medium bandgap copolymers. Polym. Int. 2020, 69, 192-205. [CrossRef]

35. Son, H.; Lu, L.; Chen, W.; Xu, T.; Zheng, T.; Carsten, B.; Strzalka, J.; Darling, S.; Chen, L.; Yu, L. Synthesis and photovoltaic effect in dithieno[2,3-d:2', $\left.3^{\prime}-d^{\prime}\right]$ benzo[1,2-b: 4,5- $\left.b^{\prime}\right]$ dithiophene-based conjugated polymers. Adv. Mater. 2013, 25, 838-843. [CrossRef] [PubMed] 
36. Li, Y.; Yao, K.; Yip, H.-L.; Ding, F.-Z.; Xu, Y.-X.; Li, X.; Chen, Y.; Jen, A.K.-Y. Eleven-membered fused-ring low band-gap polymer with enhanced charge carrier mobility and photovoltaic performance. Adv. Funct. Mater. 2014, 24, 3631-3638. [CrossRef]

37. Liang, C.; Wang, H. Indacenodithiophene-based D-A conjugated polymers for application in polymer solar cells. Org. Electron. 2017, 50, 443-457. [CrossRef]

38. Sun, Y.; Chien, S.-C.; Yip, H.-L.; Zhang, Y.; Chen, K.-S.; Zeigler, D.F.; Chen, F.-C.; Lin, B.; Jen, A.K.-Y. High-mobility low-bandgap conjugated copolymers based on indacenodithiophene and thiadiazolo[3,4-c]pyridine units for thin film transistor and photovoltaic applications. J. Mater. Chem. 2011, 21, 13247-13255. [CrossRef]

39. Chang, H.-H.; Tsai, C.-E.; Lai, Y.-Y.; Liang, W.-W.; Hsu, S.-L.; Hsu, C.-S.; Cheng, Y.-J. A new pentacyclic indacenodiselenophene arene and its donor-acceptor copolymers for solution-processable polymer solar cells and transistors: Synthesis, characterization, and investigation of alkyl/alkoxy side-chain effect. Macromolecules 2013, 46, 7715-7726. [CrossRef]

40. Zhai, W.; Zhou, E. Progress of organic photovoltaic materials based on indacenodithiophene and its derivatives. Chin. J. Org. Chem. 2016, 36, 2786-2812. [CrossRef]

41. Xu, Y.-X.; Chueh, C.-C.; Yip, H.-L.; Ding, F.-Z.; Li, Y.-X.; Li, C.-Z.; Li, X.; Chen, W.-C.; Jen, A.K.-Y. Improved charge transport and absorption coefficient in indacenodithieno[3,2-b]thiophene-based ladder-type polymer leading to highly efficient polymer solar cells. Adv. Mater. 2012, 24, 6356-6361. [CrossRef] [PubMed]

42. Xu, X.; Cai, P.; Lu, Y.; Choon, N.S.; Chen, J.; Ong, B.S.; Hu, X. Synthesis of a novel low-bandgap polymer based on a ladder-type heptacyclic arene consisting of outer thieno[3,2-b]thiophene units for efficient photovoltaic application. Macromol. Rapid Commun. 2013, 34, 681-688. [CrossRef] [PubMed]

43. Intemann, J.J.; Yao, K.; Li, Y.-X.; Yip, H.-L.; Xu, Y.-X.; Liang, P.-W.; Chueh, C.-C.; Ding, F.-Z.; Yang, X.; Li, X.; et al. Highly efficient inverted organic solar cells through material and interfacial engineering of indacenodithieno[3,2-b]thiophene-based polymers and devices. Adv. Funct. Mater. 2014, 24, 1465-1473. [CrossRef]

44. Wang, M.; Hu, X.; Liu, L.; Duan, C.; Liu, P.; Ying, L.; Huang, F.; Cao, Y. Design and synthesis of copolymers of indacenodithiophene and naphtho[1,2-c:5,6-c]bis(1,2,5-thiadiazole) for polymer solar cells. Macromolecules 2013, 46, 3950-3958. [CrossRef]

45. Xu, X.; Li, Z.; Bäcke, O.; Bini, K.; James, D.I.; Olsson, E.; Andersson, M.R.; Wang, E. Effects of side chain isomerism on the physical and photovoltaic properties of indacenodithieno[3,2-b]thiophene-quinoxaline copolymers: Toward a side chain design for enhanced photovoltaic performance. J. Mater. Chem. A 2014, 2, 18988-18997. [CrossRef]

46. Wang, K.; Zhao, Y.; Tang, W.; Zhang, Z.-G.; Fu, Q.; Li, Y. High open-circuit voltage polymer solar cells based on D-A copolymer of indacenodithiophene and fluorine-substituted benzotriazole. Org. Electron. 2004, 15, 818-823. [CrossRef]

47. Cai, P.; Xu, X.; Sun, J.; Chen, J.; Cao, Y. Effects of including electron-withdrawing atoms on the physical and photovoltaic properties of indacenodithieno[3,2-b]thiophene-based donor-acceptor polymers: Towards an acceptor design for efficient polymer solar cells. RSC Adv. 2017, 7, 20440-20450. [CrossRef]

48. Cai, Y.; Zhang, X.; Xue, X.; Wei, D.; Huo, L.; Sun, Y. High-performance wide-bandgap copolymers based on indacenodithiophene and indacenodithieno[3,2-b]thiophene units. J. Mater. Chem. C 2017, 5, 7777-7783. [CrossRef]

49. Lee, W.; Jung, J.W. A wide band gap polymer based on indacenodithieno[3,2-b]thiophene for high performance bulk heterojunction polymer solar cells. J. Mater. Chem. A 2017, 5, 712-719. [CrossRef]

50. Wang, X.; Sun, Y.; Chen, S.; Guo, X.; Zhang, M.; Li, X.; Li, Y.; Wang, H. Effects of $\pi$-conjugated bridges on photovoltaic properties of donor- $\pi$-acceptor conjugated copolymers. Macromolecules 2012, 45, 1208-1216. [CrossRef]

51. Guo, X.; Zhang, M.; Huo, L.; Xu, F.; Wu, Y.; Hou, J. Design, synthesis and photovoltaic properties of a new D- $\pi$-A polymer with extended $\pi$-bridge units. J. Mater. Chem. 2012, 22, 21024-21031. [CrossRef]

52. Xu, Y.-X.; Chueh, C.-C.; Yip, H.-L.; Chang, C.-Y.; Liang, P.-W.; Intemann, J.J.; Chen, W.-C.; Jen, A.K.-Y. Indacenodithieno[3,2-b]thiophene-based broad bandgap polymers for high efficiency polymer solar cells. Polym. Chem. 2013, 4, 5220-5223. [CrossRef] 
53. Gedefaw, D.; Tessarolo, M.; Zhuang, W.; Kroon, R.; Wang, E.; Bolognesi, M.; Seri, M.; Muccini, M.; Andersson, M.R. Conjugated polymers based on benzodithiophene and fluorinated quinoxaline for bulk heterojunction solar cells: Thiophene versus thieno[3,2-b]thiophene as $\pi$-conjugated spacers. Polym. Chem. 2014, 5, 2083-2093. [CrossRef]

54. Zuo, G.; Li, Z.; Zhang, M.; Guo, X.; Wu, Y.; Zhang, S.; Peng, B.; Wei, W.; Hou, J. Influence of the backbone conformation of conjugated polymers on morphology and photovoltaic properties. Polym. Chem. 2014, 5, 1976-1981. [CrossRef]

55. Kim, J.-H.; Park, J.B.; Shin, S.A.; Hyun, M.H.; Hwang, D.-H. Low-bandgap copolymers consisting of 2,1,3-benzoselenadiazole and carbazole derivatives with thiophene or selenophene $\pi$-bridges. Polymer 2014, 55, 3605-3613. [CrossRef]

56. Kim, J.-H.; Park, J.B.; Xu, F.; Kim, D.; Kwak, J.; Grimsdaled, A.C.; Hwang, D.-H. Effect of $\pi$-conjugated bridges of TPD-based medium bandgap conjugated copolymers for efficient tandem organic photovoltaic cells. Energy Environ. Sci. 2014, 7, 4118-4131. [CrossRef]

57. Zhou, P.; Dang, D.; Fan, J.; Xiong, W.; Yang, C.; Tan, H.; Wang, Y.; Liu, Y.; Zhu, W. Increasing thiophene spacers between thieno[3,2-b] thiophene and benzothiadiazole units in backbone to enhance photovoltaic performance for their 2-D polymers. Dyes Pigments 2015, 112, 99-104. [CrossRef]

58. Lan, L.; Zhang, G.; Dong, Y.; Ying, L.; Huang, F.; Cao, Y. Novel medium band gap conjugated polymers based on naphtho[1,2-c:5,6-c]bis[1,2,3]triazole for polymer solar cells. Polymer 2015, 67, 40-46. [CrossRef]

59. Choi, M.-H.; Kim, H.Y.; Lee, E.J.; Moon, D.K. Control of molecular curvature and crystallinity of quinacridonebenzoxadiazole copolymers using different $\pi$ bridge for polymer solar cells. Polymer 2016, 91, 162-173. [CrossRef]

60. Wang, X.; Tang, A.; Chen, F.; Zhou, E. The effect of conjugated $\pi$-bridge and fluorination on the properties of asymmetric-building-block containing polymers (ABC polymers) based on dithienopyran donor and benzothiadiazole acceptors. Polym. Chem. 2017, 8, 5396-5406. [CrossRef]

61. Zhu, D.; Bao, X.; Zhu, Q.; Gu, C.; Qiu, M.; Wen, S.; Wang, J.; Shahid, B.; Yang, R. Thienothiophene-based copolymers for high-performance solar cells, employing different orientations of the thiazole group as a $\pi$ bridge. Energy Environ. Sci. 2017, 10, 614-620. [CrossRef]

62. Park, J.; Park, J.B.; Ha, J.-W.; Park, H.J.; Kang, I.-N.; Hwang, D.-H. Efficient organic photovoltaic cells based on thiazolothiazole and benzodithiophene copolymers with $\pi$-conjugated bridges. J. Polym. Sci. Part A Polym. Chem. 2018, 56, 1978-1988. [CrossRef]

63. Zou, Y.; Dong, Y.; Wu, Y.; Yang, H.; Cui, C.; Li, Y. Conjugated polymer donor with alkylthio-thiophene $\pi$-bridge for efficient polymer solar cells. Org. Electron. 2018, 63, 289-295. [CrossRef]

64. Ma, Y.; Chen, H.; Tang, Y.; Wang, J.-Y.; Ma, W.; Zheng, Q. Modulation of bulk heterojunction morphology through small $\pi$-bridge changes for polymer solar cells with enhanced performance. J. Mater. Chem. C 2018, 6, 5999-6007. [CrossRef]

65. Gao, X.; Li, Y.; Yu, L.; Hou, F.; Zhu, T.; Bao, X.; Li, F.; Sun, M.; Yang, R. The regulation of $\pi$-bridge of indacenodithiophene-based donor- $\pi$-acceptor conjugated polymers toward efficient polymer solar cells. Dyes Pigments 2019, 162, 43-51. [CrossRef]

66. Ye, L.; Xie, Y.; Weng, K.; Ryu, H.S.; Li, C.; Cai, Y.; Fu, H.; Wei, D.; Woo, H.Y.; Tan, S.; et al. Insertion of chlorine atoms onto $\pi$-bridges of conjugated polymer enables improved photovoltaic performance. Nano Energy 2019, 58, 220-226. [CrossRef]

67. He, R.; Xu, J.; Yang, Y.; Cai, P.; Chen, D.; Ying, L.; Yang, W.; Cao, Y. Dibenzothiophene-S,S-dioxide based medium-band-gap polymers for efficient bulk heterojunction solar cells. Org. Electron. 2014, 15, 2950-2958. [CrossRef]

68. Price, S.C.; Stuart, A.C.; Yang, L.; Zhou, H.; You, W. Fluorine substituted conjugated polymer of medium band gap yields 7\% efficiency in polymer-fullerene solar cells. J. Am. Chem. Soc. 2011, 133, 4625-4631. [CrossRef]

69. Stuart, A.C.; Tumbleston, J.R.; Zhou, H.; Li, W.; Liu, S.; Ade, H.; You, W. Fluorine substituents reduce charge recombination and drive structure and morphology development in polymer solar cells. J. Am. Chem. Soc. 2013, 135, 1806-1815. [CrossRef]

70. Leclerc, N.; Chávez, P.; Ibraikulov, O.A.; Heiser, T.; Lévêque, P. Impact of backbone fluorination on $\pi$-conjugated polymers in organic photovoltaic devices: A review. Polymers 2016, 8, 11. [CrossRef] 
71. Xu, X.-P.; Li, Y.; Luo, M.-M.; Peng, Q. Recent progress towards fluorinated copolymers for efficient photovoltaic applications. Chin. Chem. Lett. 2016, 27, 1241-1249. [CrossRef]

72. Wang, T.; Lau, T.-K.; Lu, X.; Yuan, J.; Feng, L.; Jiang, L.; Deng, W.; Peng, H.; Li, Y.; Zou, Y. A medium bandgap D-A copolymer based on 4-alkyl-3,5-difluorophenyl substituted quinoxaline unit for high performance solar cells. Macromolecules 2018, 51, 2838-2846. [CrossRef]

73. Rech, J.J.; Yan, L.; Peng, Z.; Dai, S.; Zhan, X.; Ade, H.; You, W. Utilizing difluorinated thiophene units to improve the performance of polymer solar cells. Macromolecules 2019, 52, 6523-6532. [CrossRef]

74. Kawashima, K.; Fukuhara, T.; Suda, Y.; Suzuki, Y.; Koganezawa, T.; Yoshida, H.; Ohkita, H.; Osaka, I.; Takimiya, K. Implication of fluorine atom on electronic properties, ordering structures, and photovoltaic performance in naphthobisthiadiazole-based semiconducting polymers. J. Am. Chem. Soc. 2016, 138, 10265-10275. [CrossRef] [PubMed]

75. Tong, J.; Li, J.; Zhang, P.; Ma, X.; Wang, M.; An, L.; Sun, J.; Guo, P.; Yang, C.; Xia, Y. Naphtho[1,2-c:5,6-c']bis[1,2,5]thiadiazole-based conjugated polymers consisting of oligothiophenes for efficient polymer solar cells. Polymer 2017, 121, 183-195. [CrossRef]

76. Guo, X.; Zhou, N.; Lou, S.J.; Smith, J.; Tice, D.B.; Hennek, J.W.; Ortiz, R.P.; Navarrete, J.T.L.; Li, S.; Strzalka, J.; et al. Polymer solar cells with enhanced fill factors. Nat. Photonics 2013, 7, 825-833. [CrossRef]

77. Carsten, B.; He, F.; Son, H.J.; Xu, T.; Yu, L. Stille polycondensation for synthesis of functional materials. Chem. Rev. 2011, 111, 1493-1528. [CrossRef]

78. Huang, L.; Zhang, G.; Zhang, K.; Peng, Q.; Wong, M.S. Temperature-modulated optimization of high-performance polymer solar cells based on benzodithiophene-difluorodialkylthienylbenzothiadiazole copolymers: Aggregation effect. Macromolecules 2019, 52, 4447-4457. [CrossRef]

79. Han, L.; Hu, T.; Bao, X.; Qiu, M.; Shen, W.; Sun, M.; Chen, W.; Yang, R. Steric minimization towards high planarity and molecular weight for aggregation and photovoltaic studies. J. Mater. Chem. A 2015, 3, 23587-23596. [CrossRef]

80. Lee, H.S.; Song, H.G.; Jung, H.; Kim, M.H.; Cho, C.; Lee, J.-Y.; Park, S.; Son, H.J.; Yun, H.-J.; Kwon, S.-K.; et al. Effects of backbone planarity and tightly packed alkyl chains in the donor-acceptor polymers for high photostability. Macromolecules 2016, 49, 7844-7856. [CrossRef]

81. Speller, E.M.; Clarke, A.J.; Luke, J.; Lee, H.K.H.; Durrant, J.R.; Li, N.; Wang, T.; Wong, H.C.; Kim, J.-S.; Tsoi, W.C.; et al. From fullerene acceptors to non-fullerene acceptors: Prospects and challenges in the stability of organic solar cells. J. Mater. Chem. A 2019, 7, 23361-23377. [CrossRef]

82. Pommerehne, J.; Vestweber, H.; Guss, W.; Mahrt, R.F.; Bässler, H.; Porsch, M.; Daub, J. Efficient two layer leds on a polymer blend basis. Adv. Mater. 1995, 7, 551-554. [CrossRef]

83. Qi, B.; Wang, J. Open-circuit voltage in organic solar cells. J. Mater. Chem. 2012, 22, 24315-24325. [CrossRef]

84. Frisch, M.J.; Trucks, G.W.; Schlegel, H.B.; Scuseria, G.E.; Robb, M.A.; Cheeseman, J.R.; Scalmani, G.; Barone, V.; Mennucci, B.; Petersson, G.A.; et al. Gaussian 09, Revision A. 01; Gaussian, Inc.: Wallingford, CT, USA, 2009.

85. Li, J.; Wang, Y.; Liang, Z.; Qin, J.; Ren, M.; Tong, J.; Yang, C.; Yang, C.; Bao, X.; Xia, Y. Non-toxic green food additive enables efficient polymer solar cells through adjusting phase composition distribution and boosting charge transport. J. Mater. Chem. C 2020. [CrossRef]

86. Güldal, N.S.; Berlinghof, M.; Kassar, T.; Du, X.; Jiao, X.; Meyer, M.; Ameri, T.; Osvet, A.; Li, N.; Destri, G.; et al. Controlling additive behavior to reveal an alternative morphology formation mechanism in polymer: Fullerene bulk-heterojunctions. J. Mater. Chem. A 2016, 4, 16136-16147. [CrossRef]

87. Wienk, M.M.; Kroon, J.M.; Verhees, W.J.H.; Knol, J.; Hummelen, J.C.; van Hal, P.A.; Janssen, R.A.J. Efficient methano[70]fullerene/MDMO-PPV bulk heterojunction photovoltaic cells. Angew. Chem. 2003, 115, 3493-3497. [CrossRef]

88. Bao, X.; Zhang, Y.; Wang, J.; Zhu, D.; Yang, C.; Li, Y.; Yang, C.; Xu, J.; Yang, R. High extinction coefficient thieno[3,4-b]thiophene-based copolymer for efficient fullerene-free solar cells with large current density. Chem. Mater. 2017, 29, 6766-6771. [CrossRef]

89. Tong, J.; An, L.; Li, J.; Lv, J.; Guo, P.; Li, L.; Zhang, P.; Yang, C.; Xia, Y.; Wang, C. Effects of alkyl side chain length of low bandgap naphtho[1,2-c:5,6-c' $]$ bis[1,2,5]thiadiazole-based copolymers on the optoelectronic properties of polymer solar cells. J. Polym. Sci. Part A Polym. Chem. 2018, 56, 85-95. [CrossRef] 
90. Li, J.; Wang, N.; Wang, Y.; Liang, Z.; Peng, Y.; Yang, C.; Bao, X.; Xia, Y. Efficient inverted organic solar cells with a thin natural biomaterial L-Arginine as electron transport layer. Sol. Energy 2020, 196, 168-176. [CrossRef]

91. Wang, Y.; Liang, Z.; Li, X.; Qin, J.; Ren, M.; Yang, C.; Bao, X.; Xia, Y.; Li, J. Self-doping n-type polymer as a cathode interface layer enables efficient organic solar cells by increasing built-in electric field and boosting interface contact. J. Mater. Chem. C 2019, 7, 11152-11159. [CrossRef]

(C) 2020 by the authors. Licensee MDPI, Basel, Switzerland. This article is an open access article distributed under the terms and conditions of the Creative Commons Attribution (CC BY) license (http://creativecommons.org/licenses/by/4.0/). 